NBER WORKING PAPER SERIES

\title{
OBJECTIVE COURSE PLACEMENT AND COLLEGE READINESS: EVIDENCE FROM TARGETED MIDDLE SCHOOL MATH ACCELERATION
}

\author{
Shaun Dougherty \\ Joshua Goodman \\ Darryl Hill \\ Erica Litke \\ Lindsay C. Page \\ Working Paper 21395 \\ http://www.nber.org/papers/w21395 \\ NATIONAL BUREAU OF ECONOMIC RESEARCH \\ 1050 Massachusetts Avenue \\ Cambridge, MA 02138 \\ July 2015, Revised April 2017
}

Previously circulated as "Early Math Coursework and College Readiness: Evidence from Targeted Middle School Math Acceleration" None of the authors have outside financial relationships relevant to this research. This research was made possible by a collaboration between the Wake County Public School System and the Strategic Data Project, housed in Harvard's Center for Education Policy Research. We are grateful for feedback from Chris Avery, David Deming, Eleanor Dillon, Anna Egalite, Maria Fitzpatrick and Melinda Sandler Morrill, as well as from seminar participants at the University of Connecticut, University of Pittsburgh, Carnegie Mellon, North Carolina State University, Columbia University, APPAM, AEFP, SREE and AERA. Melanie Rucinski provided excellent research assistance. We gratefully acknowledge institutional support from the Taubman Center for State and Local Government at Harvard. Any errors are our own. The views expressed herein are those of the authors and do not necessarily reflect the views of the National Bureau of Economic Research.

NBER working papers are circulated for discussion and comment purposes. They have not been peer-reviewed or been subject to the review by the NBER Board of Directors that accompanies official NBER publications.

(C) 2015 by Shaun Dougherty, Joshua Goodman, Darryl Hill, Erica Litke, and Lindsay C. Page. All rights reserved. Short sections of text, not to exceed two paragraphs, may be quoted without explicit permission provided that full credit, including $\odot$ notice, is given to the source. 
Objective Course Placement and College Readiness: Evidence from Targeted Middle School Math Acceleration

Shaun Dougherty, Joshua Goodman, Darryl Hill, Erica Litke, and Lindsay C. Page

NBER Working Paper No. 21395

July 2015, Revised April 2017

JEL No. I20,I24,J24

\begin{abstract}
Advanced math coursework can affect college and labor market outcomes, yet discretionary placement policies can lead to differential access at key points in the college preparatory pipeline. We examine a targeted approach to course assignment that uses prior test scores to identify middle school students deemed qualified for a college preparatory math sequence. Accelerated math placement of relatively low-skilled middle schoolers increases the fraction later enrolling in Precalculus by one-seventh, and by over one-third for female and non-low income students. Acceleration increases college readiness and intentions to pursue a bachelor's degree. Course placement rules based on objective measures can identify students capable of completing rigorous coursework but whom discretionary systems might overlook.
\end{abstract}

Shaun Dougherty

University of Connecticut

Neag School of Education

249 Glenbrook Rd.

Storrs, CT 06269

shaun.dougherty@uconn.edu

Joshua Goodman

Harvard Kennedy School

79 JFK Street

Cambridge, MA 02138

and NBER

joshua_goodman@hks.harvard.edu

Darryl Hill

Wake County Public School System

5625 Dillard Drive

Cary, NC 27518

dhill3@wcpss.net
Erica Litke

University of Delaware

erica_litke@mail.harvard.edu

Lindsay C. Page

School of Education

University of Pittsburgh

4318 Wesley W. Posvar Hall

230 South Bouquet Street

Pittsburgh, PA 15260

lpage@pitt.edu 


\section{Introduction}

Mathematics has long been regarded as essential for both individual and national economic success. Numerous microeconomic studies have shown that mathematical skills, high school coursework and college majors predict individuals' labor market earnings (Altonji, 1995; Grogger and Eide, 1995; Levine and Zimmerman, 1995; Brown and Corcoran, 1997; Weinberger, 1999; Rose, 2004; Altonji et al., 2012). Standardized measures of nations' math skills also strongly predict macroeconomic growth (Hanushek and Woessmann, 2015). Concerns triggered by the launch of Sputnik in 1957 and by the publication of "A Nation at Risk" in 1983 show that policymakers have for decades been calling for increased proficiency in math among American students as a national imperative (Gardner et al., 1983; Tate, 1997).

Schools have, however, struggled to increase the proportion of students, particularly those from disadvantaged backgrounds, who successfully complete a sequence of math courses that prepare them for either the workforce or for quantitative training at the postsecondary level. Recent efforts to improve access to rigorous coursework have focused on early exposure to Algebra I, in part because it often precedes a sequence of courses culminating in Calculus and is thus seen as a gatekeeper course required for college-preparatory math (Adelman, 2006). ${ }^{1}$ Such efforts have been motivated in part by observational research suggesting that early exposure to Algebra $I$ is associated with future academic success (Smith, 1996; Gamoran and Hannigan, 2000; Stein et al., 2011) and that completion of the follow-on coursework sequence strongly predicts later college success (Long et al., 2012).

Not all students have equal access to Algebra I at earlier grades, however, in part because of differences in academic skills and school offerings (Conger et al., 2009). Even conditional on such factors, talented but disadvantaged students may be overlooked by the process through which math courses assignments are made, as course placement generally involves substantial discretion by school officials. To address these issues, many school districts and states have implemented universal algebra policies that mandate all ninth, or even eighth, graders enroll in Algebra I (Silver, 1995). Partly as a result of such policies, eighth grade Algebra I enrollment rates have more than doubled in the past two decades, from 15 percent in 1990 to 34 percent in 2012, with additional growth in the proportion of eighth graders completing even higher math courses. ${ }^{2}$ Nevertheless, substantial gaps by race and income remain (Stein et al., 2011).

\footnotetext{
${ }^{1}$ The traditional sequence until recently has been Algebra I, Geometry, Algebra II, Precalculus and Calculus. The new Common Core standards have begun to change the early part of this sequence involved but has not affected the broader debate over whether and how to expose students to more rigorous coursework in early grades.

${ }^{2}$ See Figure 33 of The National Center for Education Statistics' 2013 publication "The Nation's Report Card: Trends in Academic Progress 2012."
} 
The "Algebra-for-All" movement has also generated concerns that universal access may harm both those students under-prepared for more rigorous coursework and more highly skilled students whose curricula are diluted to adapt to the new skill-level of the average enrollee (Loveless, 2008; Schneider, 2009). Such universal policies have begun to fall out of favor. For example, in 2013, California backed away from a state requirement enacted in 2008 that all eighth graders take Algebra I. Instead, some systems have begun to explore a targeted approach that increases access to college-preparatory math coursework but only for students deemed sufficiently prepared for such rigor. We investigate one such model of targeted middle school math acceleration implemented in the 2010-11 school year by North Carolina's Wake County Public School System (WCPSS). Specifically, we focus on the impact of the policy on math course enrollment and success for students at the margin of acceleration.

WCPSS, concerned about both levels of and inequitable access to rigorous math coursework, instituted a targeted enrollment strategy designed to increase advanced math course-taking for students predicted to succeed in such courses. The district announced that assignment to an accelerated track leading to Algebra I in eighth grade would be based on a student's predicted probability of success in that subject. Specifically, if a student's available prior test scores predicted at least a 70 percent probability of passing a standardized algebra test, the student would be recommended for enrollment in that accelerated track. That threshold corresponded to about the 20th percentile of the district's skill distribution, implying that 80 percent of students were eligible for acceleration under the new policy. ${ }^{3}$ The remaining 20 percent would take coursework leading to Algebra I in ninth grade.

We study the two earliest cohorts affected by the policy, for whom eligible students were initially accelerated in seventh grade to Pre-Algebra and whom we can observe through eleventh grade. A regression discontinuity design comparing those just above and below the eligibility threshold allows us to document five important facts about the relatively low-skilled students at the margin of acceleration. First, acceleration has no clear short-run impact on test scores. Second, accelerated students generally pass but rarely excel in their more rigorous courses, largely earning Cs and Ds. Third, one-seventh of students initially accelerated in seventh grade remain in the accelerated track to take Precalculus by eleventh grade, suggesting a fairly but not totally leaky pipeline. Fourth, conditional on initial acceleration, persistence rates in the pipeline differ greatly by income and gender, with acceleration increasing Precalculus enrollment rates by over 40 percentage points for non-low income students and over 30 percentage points for female students, relative to nearly

\footnotetext{
${ }^{3}$ Because WCPSS students outperform North Carolina's students on average, the marginal student affected by the policy was in roughly the 35 th percentile of the statewide distribution.
} 
no impact on low income and male students. Fifth, middle school math acceleration improves college readiness scores and college aspirations, increasing the fraction of students intending to enroll in four-year colleges by over 20 percentage points. As we discuss, these impacts on college readiness may be driven by a combination of exposure to the advanced mathematics curriculum as well as exposure to a higher-performing peer group, on average. Such changes to course exposure and peer composition are likely a feature of many targeted acceleration policies that seek to move lower-performing students into a more homogeneously high-performing setting.

These findings make three primary contributions to the literature. First and most importantly, we show that basing course assignment on objective measures of student skill helps identify students whom, conditional on ability, a discretionary system might overlook but who are capable of persisting in a college preparatory math track. Just as disadvantaged students are assigned to lower quality teachers (Jackson, 2009; Sass et al., 2012; Clotfelter et al., 2005, 2006; Kalogrides and Loeb, 2013), so too are they assigned to less rigorous coursework, even compared to their schoolmates of similar academic skill. We show in Dougherty et al. (2015) that the new assignment rule substantially diminished income and race gaps in course assignment, similar to recent work on universal screening policies to remedy such gaps in assignment to gifted and talented classrooms (Card and Giuliano, 2015; Grissom and Redding, 2016). We show here that initial acceleration leads to long-run increases in the fraction of students pursuing college preparatory coursework, particularly for female and non-low income students. In other settings, switching to decision processes focused on objective quality measures has improved success rates for otherwise overlooked individuals (Blank, 1991; Goldin and Rouse, 2000). We provide evidence of similar results in an educational setting.

Second, we provide the first estimated impacts of a clearly defined, targeted math acceleration policy, complementing prior studies of universal or more vaguely defined policies to increase early exposure to algebra. In 1997, Chicago eliminated remedial coursework and required that all ninth graders take algebra. This led to a decline in both course grades and test scores of high-skilled students, perhaps because the reform exposed such students to lower-skilled peers and less rigorous curricula (Allensworth et al., 2009; Nomi, 2012). California's 2008 decision to make algebra the benchmark test for eighth grade accountability purposes substantially increased eighth grade algebra enrollment, which in turn led to lower tenth grade test scores, particularly in larger school districts (Domina, 2014). Recent attempts by two districts in North Carolina to accelerate algebra to eighth grade have resulted in lowered course performance, particularly for the lowest-skilled students (Clotfelter et al., 2015). The targeted acceleration model studied here did not clearly lower test scores among the lowest performing students eligible for advancement and thus suggests one 
potential advantage over universal acceleration policies. ${ }^{4}$ That these marginal students struggle to earn high grades in harder courses is a common theme across all such interventions. We nonetheless expect targeted approaches to grow in prevalence, making this research particularly timely.

Third, the threshold-based assignment rule allows us to document precisely how initial acceleration affects the marginal student's progress through the sequence of college preparatory math coursework that matters for long-run outcomes. We estimate that one-third of remaining accelerated students return to the non-accelerated track each year, so that the initial impact of acceleration on coursework decays over time. This leaky pipeline is consistent with evidence from California's eighth grade algebra push (Liang et al., 2012) and from other North Carolina districts (Clotfelter et al., 2015). We complement prior research focused on test scores and course grades by emphasizing students' coursework trajectories, given increasing quasi-experimental evidence that improved high school math coursework can have substantial effects on high school graduation rates, college enrollment rates and labor market earnings, both for relatively low-skilled students (Goodman, 2012; Cortes et al., 2015) and relatively high-skilled ones (Joensen and Nielsen, 2009; Jackson, 2010; Smith et al., 2015). That this policy increased the share of students completing college preparatory math near the end of high school suggests it has the potential for longer-run impacts. That non-low income and female students persist at higher rates in this pipeline may point to the importance of personal skills or family resources in explaining why some students succeed in the context of increased curricular rigor. It also points to the potential need for additional supports to encourage greater rates of persistence among students who struggle in that context.

The remainder of the paper is structured as follows. In Section 2, we provide a history and detailed description of the middle school math acceleration policy in WCPSS. We then describe our data and empirical strategy in Section 3. In Section 4, we present estimates of the impact of acceleration on a variety of student outcomes, including test scores, subsequent coursework and college readiness measures. We conclude in Section 5 with a discussion of these results and implications for policy, practice and future research.

\footnotetext{
${ }^{4}$ We believe there are two reasons we do not find the negative achievement effects seen in Clotfelter et al. (2015). First, the WCPSS intervention was targeted, so that marginal students were placed largely into classes with at least moderately-skilled peers, in contrast to the universal policies studied in that prior work, where low-skilled students may have been placed into classes largely populated by similarly low-skilled peers. Peer effects, as well as teachers abilities to tailor classes to a more appropriately skilled set of students, may thus drive some of these differences. Second, because WCPSS is higher performing than the districts studied in that prior work, the marginal student here is closer to the middle of the distribution in that work. This may also explain why we do not see negative effects, given that the policy we study excludes from acceleration students with skills so low they are not predicted to succeed in Algebra I.
} 


\section{Math Acceleration in Wake County}

District leaders in WCPSS initiated the targeted enrollment policy in response to two concerns. First, as of the 2009-10 school year, only 30 percent of WCPSS eighth graders were enrolled in Algebra I. Second, eighth graders who did enroll in Algebra I were not demographically representative of the district. The school board, partnering with a task force focused on economically disadvantaged students, sought a strategy to provide equitable access to appropriate and rigorous math courses in the middle grades. In particular, the district hoped to increase the disproportionately low rates of enrollment in accelerated math coursework among students who were black, Hispanic or from low-income households. The district assumed that increasing students' access to such coursework in middle school would increase their likelihood of completing a rigorous, college-preparatory sequence of high school math courses. District leaders were reluctant to implement a universal policy assigning all eighth graders to Algebra I due to concerns that not all students had taken appropriate preparatory coursework and concerns that middle schools lacked sufficient numbers of teachers prepared to teach such classes.

The district ultimately implemented a targeted enrollment strategy, starting in the 2010-11 school year, that identified students eligible for accelerated math using a prediction model from the SAS Institute's Education Value-Added Assessment System (EVAAS). After each academic year, the EVAAS model generates for each student a predicted probability of success on the North Carolina Algebra I end-of-course exam, based on all of the student's available prior standardized end-of-grade test scores. ${ }^{5}$ The district stipulated that students with a 70 percent or higher predicted probability of Algebra I success would be recommended for placement into accelerated math courses. Use of the EVAAS predicted probability had two perceived advantages. First, it helped identify students who were thought to be well-prepared for such coursework. Second, because EVAAS is an objective measure, the district believed it could help identify students who might otherwise be overlooked as a result of variation in course grading practices and subjective beliefs about which students are capable of success in accelerated math courses.

Standards for sixth graders' accelerated math course, called "Accelerated Math", included all of the sixth grade content for the non-accelerated course and roughly one half of the content for the non-accelerated seventh grade course. Similarly, standards for seventh graders' accelerated course, called "Pre-Algebra", included the remaining content for the non-accelerated seventh grade course and all content of the non-accelerated eighth grade course. The subject matter of the sixth and seventh grade accelerated courses overlaps substantially with the standards tested on the North

\footnotetext{
${ }^{5}$ For purposes of the policy studied here, success is defined as achieving Level III (of four levels) on the Algebra I end-of-course exam.
} 
Carolina End-of-Grade examinations and content review for those tests is included in each course outline. Eighth graders' accelerated course, "Algebra I", covered typical standards from a first high school algebra course but, as of 2012-13, became an integrated course beginning the three-year high school sequence suggested by the Common Core State Standards for Mathematics. Content review for the eighth grade End-of-Grade math examination is also part of the course outline.

Due largely to this new policy, the share of middle school students in accelerated math rose from 40 percent to nearly 70 percent within two years of the policy's implementation (Dougherty et al., 2015). By 2012-13, nearly all EVAAS-eligible students were enrolled in accelerated math, while acceleration rates remained largely unchanged for students deemed ineligible by the new policy. Acceleration rates rose substantially for both low income and non-low income students, though a large income gap in acceleration persisted in part because of the large income gap in EVAAS scores. A similar pattern is seen when comparing black and Hispanic students to white and Asian students. Levels and trends in math acceleration look quite similar by gender.

\section{Data and Empirical Strategy}

\subsection{Data and Summary Statistics}

WCPSS first implemented the acceleration policy in the 2010-11 school year. In the first two years of implementation, WCPSS first applied the assignment rule to rising 7 th graders, placing them in Pre-Algebra if determined to be eligible for acceleration. We refer to these two cohorts as the 2011 and 2012 cohorts, as these represent the spring of the year they were first in 7th grade and thus potentially affected by the new policy. We focus on these two cohorts because we can observe them through at least the start of eleventh grade and because they share a common treatment, namely initial acceleration in 7th grade. Subsequent cohorts, whom we discuss briefly below, were first accelerated in sixth grade. Our main analysis sample thus consists of WCPSS students with valid EVAAS scores who entered 7th grade in the 2010-11 and 2011-12 school years.

Using data from the WCPSS longitudinal student information system, we follow such students from the end of fifth grade, when they are first assigned EVAAS scores, through middle and high school, when our outcomes of interest are measured. We can track students as long as they stay within WCPSS. ${ }^{6}$ The data include student-level EVAAS scores, generated annually for rising sixth, 7 th and eighth graders as further standardized test scores are incorporated into the calculation. The data also contain information on student demographics, such as gender, free or reduced price lunch

\footnotetext{
${ }^{6}$ Rates of departure from WCPSS were low and not impacted by course placement. We show later that our primary results are not sensitive to the way in which such missing data is dealt with.
} 
status, and race/ethnicity. We utilize such variables as controls in some regression specifications and to explore heterogeneity in program impacts.

We observe each student's middle school and high school coursework transcripts. We can observe the math courses in which students enroll and thus their acceleration status based on course titles. Because classrooms can be uniquely identified and linked to both students and teachers, we can construct measures of peer composition, such as class size or average prior achievement, and teacher characteristics, such as years of experience or value-added. These classroom-level measures help us characterize in greater detail the various channels through which acceleration may affect student outcomes.

We investigate three important categories of outcomes that may be affected by math acceleration. First, we consider math course enrollment in subsequent grades. The longest-run course outcome we measure is enrollment in Precalculus by eleventh grade, which indicates the student is still on the accelerated track leading to twelfth grade calculus. Second, we observe course grades, which allow us to determine whether accelerated students are excelling in, just passing or failing their more rigorous coursework. Third, we observe two sets of standardized test scores. North Carolina's end-of-grade (EOG) exams in math and reading comprehension, administered in 3rd through eighth grades regardless of course enrollment, provide a common assessment allowing us to estimate whether acceleration affects achievement in middle school. All students in these cohorts also take the ACT's tenth grade PLAN exam, a precursor to the ACT that is intended to measure college readiness. We observe students' PLAN test scores, as well as their answers to questions about post-high school educational intentions.

Table 1 contains summary statistics for WCPSS students. Column 1, which contains all students in the 2011-12 cohorts, shows that 43 percent of students are low income and 40 percent are black or Hispanic. The average EVAAS score among these students was 83.6, and nearly 80 percent of them were eligible for acceleration according to the new rule. The threshold of 70 thus separated the lowest quintile of the skill distribution from the upper four quintiles. Though not all eligible students were accelerated, most were, resulting in nearly two-thirds of WCPSS seventh graders in these two cohorts enrolling in Pre-Algebra.

Columns 2 and 3 divide the sample by initial acceleration status. Relative to non-accelerated students, accelerated students are substantially less likely to be low income, black or Hispanic, have much higher prior test scores, are in classes with much higher-scoring peers, and have much better outcomes as measured by test scores, subsequent advanced math course enrollment and college intentions. Column 4 shows our main regression discontinuity sample, defined as those students within 15 EVAAS points of the eligibility threshold. Because the threshold represents roughly the 
20th percentile of the skill distribution in WCPSS, such students have lower academic skills and are more likely to be low income or black or Hispanic than the average WCPSS student.

Before turning toward estimation of the impact of acceleration on later outcomes, we note our previous finding that the new policy reduced the role of demographic characteristics in course assignment (Dougherty et al., 2015). For untreated cohorts, even conditional on academic skill, low income and black or Hispanic students were less likely to be accelerated than their peers. For the most recent treated cohorts, conditional on academic skill, the income gap in acceleration was one-third the size of the gap in earlier cohorts and there was no statistically significant racial gap. Black and white students in the same school, same grade and of the same academic skill appear now to have equal exposure to accelerated math coursework. The new EVAAS score-based assignment rule thus succeeded in reducing the role of income and race in the math acceleration decision by emphasizing the role of academic skill. ${ }^{7}$

\subsection{Regression Discontinuity Design}

We now turn to estimation of the impacts of math acceleration on student outcomes. The substantial differences in academic skill and other factors between accelerated and non-accelerated students would severely bias a simple comparison of these two groups' outcomes. To cleanly identify the impact of math acceleration on course enrollment, course grades and test scores, we exploit the fact that WCPSS chose an EVAAS predicted probability of 70 percent as the threshold for assignment to accelerated math coursework. This fact allows us to use a regression discontinuity (RD) design to compare outcomes of students just above and below that threshold, two groups of students who are nearly identical except that the former group was recommended for acceleration while the latter was not. As such, comparison of these two groups near the threshold should yield estimates unbiased by differences in prior academic achievement or other student characteristics.

For the RD approach to yield valid causal inference, subjects must not be able to precisely control their EVAAS score relative to the threshold. Three facts support this assumption. First, while WCPSS selected the cutoff criteria of 70 percent, SAS was responsible for generating the probability values and the underlying model is not made public. Second, EVAAS scores are a function of performance on multiple prior standardized tests and students have neither sufficient technical knowledge of the policy nor sufficient capability to manipulate their own test performance to precisely influence their placement relative to the threshold. Third, for the earliest cohorts, students

\footnotetext{
${ }^{7}$ The policy substantially narrowed income and race gaps conditional on academic skill but had less of an impact on unconditional gaps because a high proportion of low income and minority students were below the eligibility threshold. In other words, the policy helped previously overlooked students in the top four-fifths of the skill distribution but did not address the bottom fifth, which is disproportional low income and minority.
} 
sat for standardized tests prior to the development of the prediction model or assignment policy and could not have anticipated it being implemented. The density of EVAAS scores near the threshold, shown graphically in Figure A.1, is quite smooth across the whole sample and near the threshold, suggesting no obvious manipulation of EVAAS scores. Densities disaggregated by cohort look similarly smooth.

Students could qualify for placement into seventh grade Pre-Algebra by receiving an EVAAS score of at least 70 at the end of 5 th grade or at the end of sixth grade. If either score met that threshold, the student was considered eligible. We thus implement our regression discontinuity design by assigning each student a re-centered maximum of those two scores:

$$
E V A A S=\max \left(E V A A S_{5}, E V A A S_{6}\right)-70
$$

Students for whom this EVAAS score is negative never qualified at the end of either grade, while those whose score is non-negative qualified after at least one of those grades. This maximum score thus transforms the two underlying EVAAS scores into a unidimensional variable that can be used in a traditional RD framework.

Because compliance with the assignment rule was imperfect, we use a fuzzy regression discontinuity design by implementing a two-stage approach to estimate the effect of math acceleration on various outcomes (Imbens and Lemieux, 2008). In the first stage, the threshold provides exogenous variation in the probability that a student is on the accelerated math track. We use local linear regressions so that the first stage takes the form:

$$
\text { Accelerated }_{i c s}=\alpha_{0}+\alpha_{1} \text { Eligible }_{i c s}+\alpha_{2} E V A A S_{i c s}+\alpha_{3}\left(\text { Eligible }_{*} \text { EVAAS }\right)_{i c s}+\gamma_{c s}+\mu_{i c s}
$$

Here, Accelerated indicates that student $i$ in cohort $c$ and school $s$ was initially placed in an accelerated math course, meaning Pre-Algebra in 7th grade. The variable Eligible indicates whether a student was above the EVAAS eligibility threshold. The running variable EVAAS is that student's re-centered maximum EVAAS score as defined above. Including that term, as well as its interaction with Eligible, fits straight lines of potentially different slopes on either side of the threshold. The coefficient $\alpha_{1}$ represents the difference in acceleration probabilities between students just above and just below the eligibility threshold. Cohort-by-school fixed effects $\gamma$ ensure that students are being compared to their within-school peers, to control for differences in course offerings and assignment processes across schools and time. ${ }^{8}$

\footnotetext{
${ }^{8}$ Inclusion of the cohort-by-school fixed effects has little impact on the magnitude of the estimated coefficients but
} 
We use predicted values from the first stage to then estimate the following second-stage equation:

$$
Y_{i c s}=\beta_{0}+\beta_{1} \text { Accelerated }_{i c s}+\beta_{2} E V A A S_{i c s}+\beta_{3}(\text { Eligible } * E V A A S)_{i c s}+\lambda_{c s}+\epsilon_{i c s}
$$

Here, $Y$ represents a variety of student outcomes. The coefficient $\beta_{1}$ estimates the impact of initial math acceleration on such subsequent outcomes for compliers, those students whose acceleration status was affected by the eligibility threshold itself (Angrist et al., 1996). These estimates represent local average treatment effects for students near the 20th percentile of the skill distribution in Wake County.

For our primary specification, we estimate these local linear regressions using a rectangular kernel, demographic controls, and standard errors clustered by initial middle school. ${ }^{9}$ The demographic controls include gender, race, low income status, age at middle school entry, and special education and limited English proficiency status. We use a bandwidth of 15 EVAAS points because, for most of our outcomes, it is quite close to the reduced form optimal bandwidths suggested by Imbens and Kalyanaraman (2012). We later show that our results are robust to alternate bandwidths, including the Imbens-Kalyanaraman bandwidth, as well as to the exclusion of demographic covariates as controls. ${ }^{10}$

That inclusion of covariates does not affect our central estimates is unsurprising given that the inability to manipulate the EVAAS score suggests students' demographic characteristics should be balanced across the threshold. We confirm this in Table A.1, which tests for discontinuities in demographic characteristics at the threshold by running our first-stage specification with various covariates as outcomes. The samples appear balanced across nearly all covariates. Only low income status shows a marginally significant imbalance using our preferred bandwidth, which we suspect is spurious. To test the joint balance of all of these covariates, we generate predicted math and reading scores for the treated cohorts based on coefficients from a regression of those outcomes on these covariates for the untreated 2008 cohort. The final two rows show no evidence of differences in predicted test scores across the threshold.

The regression discontinuity design allows us to make valid causal claims about the impact of the policy and the associated course advancement on students' subsequent outcomes. A clear limitation is that our findings and associated implications are generalizable most directly only to

substantially increases their precision.

${ }^{9}$ EVAAS scores are computed to one-tenth of a percentage point and are thus nearly continuous, so that we have no need to cluster by score as suggested by Lee and Card (2008).

${ }^{10}$ Though not shown here, the results presented below are also robust to optimal bandwidths selected by the methods proposed in Ludwig and Miller (2007) and Calonico et al. (2014). They are also robust to the use of a triangular kernel. 
those students at the margin of meeting the policy criteria. That is, we are able to understand the impact of being on the margin of eligibility and therefore placed in the accelerated math trajectory. Nonetheless, understanding the impact among this marginal set of students is important. If these students fare worse as a result of advancement, the district may be inclined to develop more stringent placement standards. On the other hand, if these marginal students fare better, the district may be inclined to relax the standard and open the opportunity to even more students. In the absence of a discernible learning impacts, districts may nevertheless be pleased with the more representative demographic composition of advanced classes. In short, there are important policy implications for understanding effects precisely at the EVAAS threshold relevant to the policy in question.

\subsection{First Stage Results}

We test the strength of the first stage relationship between eligibility and math acceleration in Table 2, where the outcome is enrollment in 7th grade Pre-Algebra. The first row shows that, across specifications that vary in bandwidth and inclusion of demographic controls, students just above the eligibility threshold are substantially more likely to be accelerated than those below it. Our preferred specification, in column 3, indicates that eligibility boosts 7 th grade Pre-Algebra enrollment by 24 percentage points, which represents a tripling of the acceleration rate relative to the 12 percent rate for students just below the threshold. ${ }^{11}$ The F-statistic for the instrument in our preferred specification exceeds 50, suggesting that eligibility is a strong source of exogenous variation in acceleration status. This can also be seen graphically in Figure 1, which shows a substantial and visually obvious discontinuity and suggests the relationship between acceleration and EVAAS is fairly linear.

The remaining rows of Table 2 show first stage estimates separately by income, race and gender. We see no evidence that the relationship between eligibility and acceleration varies by income or gender, with remarkably similar point estimates across all specifications. We do, however, see some evidence that the relationship varies by race, with generally stronger first stages for black and Hispanic students than for white and Asian students. Figures A.2, A.3 and A.4 show these first stages graphically, with remarkable overlap between the two sets of observations in each figure. The slight difference in first stage strength by race appears to be driven by the fact the just eligible white and Asian students are, if anything, less likely to be accelerated than their black and Hispanic peers. Overall, acceleration rates conditional on academic skill appear to be quite similar

\footnotetext{
${ }^{11}$ Most non-compliance was apparently driven by students and families opting out of accelerated courses to which they were assigned. Evidence from the time suggests fewer than five percent of non-compliance cases were due to schools not following the assignment rule.
} 
by demographic subgroup, so that the assignment rule appears to have a fairly homogeneous impact on math acceleration rates.

Before turning to the impact of math acceleration on student outcomes, we document a variety of channels potentially responsible for such impacts. The most obvious channel through which math acceleration might affect students is through exposure to a more rigorous curriculum, something we cannot measure precisely beyond categorizing courses based on their titles. We can, however, observe other aspects of the classroom experience to which students are exposed, including the characteristics of the peers and teacher in each student's math classroom. In each classroom, we can characterize the mean and standard deviation of peers' math skills as measured by 5 th grade math scores, the total class size, and the fraction of students who are female and black or Hispanic. For many of the students' math teachers, we can also identify value-added measures of teacher quality, years of experience, race and gender.

Table 3 shows instrumental variables estimates of the effect of initial math acceleration on the characteristics of a student's initial math classroom. Panel A shows that acceleration exposes students to peers who are 0.8 standard deviations higher in math skill but has no impact on the within-classroom variance of peer skills. It substantially increase class size, by five students, consistent with the observation by Lazear (2001) that more academically skilled students can be placed in larger classes. Accelerated students end up in math classes substantially less populated by black or Hispanic students but similar in terms of gender composition. Panel B shows that acceleration has little impact on average teacher quality, though it may reduce the probability of having a lowperforming teacher, defined as one whose value-added measure "does not meet expected growth."12 Acceleration has no discernible impact on the experience level, race or gender of students' math teachers. ${ }^{13}$

In total, these results suggest that acceleration exposes students to higher skilled peers, which might have positive effects, but also to larger class sizes, which might have negative effects. Observable teacher characteristics are generally similar across accelerated and non-accelerated students. The impact of a more challenging curriculum is also theoretically ambiguous. Based on these results, it is worth noting that because of the structure of the policy, students on different sides of the EVAAS threshold had mathematics classroom experiences that differed not only in terms of curriculum and course content but also in terms of the student composition of the class-

\footnotetext{
12“"Expected growth" represents a test score gain that North Carolina deems standard for a given student. Teachers' value-added measures then represent an average of students' growth. In WCPSS, about one-fifth of teachers fall into this category of not making expected growth.

${ }^{13}$ These results are not biased by our inability to link a small number of students to teachers, as the probability of such linkage is itself unaffected by the eligibility threshold.
} 
room itself. In this respect, the treatment we are assessing is multidimensional and not necessarily the exclusive effect of a more advanced mathematics curriculum.

We also note that WCPSS, anticipating newly accelerated students might struggle in their classes, offered additional, optional tutoring services for students with EVAAS scores between 70 and 80 . The treatment effect we estimate at the 70 threshold may thus consist partially of such tutoring services. Unfortunately, we have little clear evidence on take-up rates for these services, either in aggregate or for individual students. Though not shown here, we find no evidence of discontinuities in any outcomes at the 80 threshold, implying either that tutoring services were ineffective or that take-up rates were too low to generate detectable effects.

\section{Math Acceleration and Student Outcomes}

\subsection{Test Scores}

Having established that the eligibility threshold provides a strong source of exogenous variation in the probability of being in the accelerated math track, we now estimate the impact of such acceleration on short-run standardized test scores. ${ }^{14}$ Figure 2 shows the reduced form relationship between EVAAS scores and end-of-grade math test scores as measured in 7th grade. Unsurprisingly, prior achievement as measured by EVAAS scores has a clear and positive relationship with subsequent achievement. There is, however, no visually apparent discontinuity in test scores at the eligibility threshold. The estimate in the first row of column 1 of Table 4 confirms this, showing no statistically significant impact of 7th grade acceleration on math achievement at the end of that school year. The top row of Table A.2 shows that this small point estimate and lack of statistical significance is robust to a variety of other specifications. The remaining rows show little clear evidence of subgroup effects. The only exception, that acceleration increases non-low income students' scores substantially, appears somewhat sensitive to the bandwidth selected.

This lack of clear achievement impact is unlikely to be driven by differential selection into test-taking, as column 2 of Table 4 shows no difference in testing rates across the threshold. Math acceleration does not appear to have spillover effects onto reading skills, given no apparent impact on end-of-grade reading test scores in column 3. The second row shows no apparent impacts of 7 th grade acceleration on achievement at the end of eighth grade. Because the point estimates in column 1 are close to zero but imprecisely estimated, in column 4 we include an additional cohort, those students who started 7th grade in 2012-13. Such students accelerated starting in sixth grade.

\footnotetext{
${ }^{14}$ All test scores have been standardized within grade and year to have mean zero and standard deviation one.
} 
Using sixth grade acceleration as the treatment variable for these students, along with sixth and seventh grade test scores as outcomes, allows us to increase the precision of our estimated impacts of math acceleration on achievement after one and two years. Point estimates are still fairly close to zero and we can rule out positive impacts of more than 0.2 standard deviations. Overall, we see little clear evidence that targeted acceleration affected math or reading standardized test scores, in contrast to universal acceleration policies that often generate negative achievement effects.

Why does math acceleration not have clearer impacts on short-run standardized test scores? Our estimated test score impacts are relatively imprecise so we cannot exclude the possibility of rather sizable positive or negative impacts. One explanation for imprecision may be that curricular differences between the advanced and non-advanced course sequences may be more modest than course titles suggest, so that students in each track are exposed to similar material and are thus similarly prepared for the end-of-grade assessments. The end-of-grade tests may also not be sensitive to the curricular differences that do exist between these two course levels, if topics covered in the advanced track but not in the lower track are not present on the exam. Finally, given that Clotfelter et al. (2015) find heterogeneous impacts by student skill, it may be that WCPSS set the eligibility threshold at a point in the skill distribution where the marginal student's test scores are neither helped nor harmed by this intervention.

\subsection{Coursework}

The primary goal of math acceleration policies is to increase the number of students prepared for college-level math. Table 5 explores the impact of placement into Pre-Algebra in seventh grade on students' coursework trajectories through the start of eleventh grade. Each column shows a different grade level, while the first three rows indicate whether students were still enrolled in the accelerated track in that grade, whether they passed an accelerated course, and whether they earned an A or B in an accelerated course. These instrumental variables estimates can be interpreted as changes in the probability of these outcomes for the marginal student induced into seventh grade Pre-Algebra by the new policy. Alternatively, they can be interpreted as the fraction of initial compliers who succeed at the given outcome. Column 1 shows that, of the students induced by the new policy into seventh grade Pre-Algebra, 90 percent passed that Pre-Algebra course but only 11 percent earned a B or better. This suggests that the vast majority of marginal students are earnings Cs and Ds in their Pre-Algebra course, passing but not excelling in it.

In part because of this relatively poor academic performance, only 62 percent of the initially accelerated students remain in the accelerated track the next year to take Algebra I in eighth grade, 
as the first row shows. ${ }^{15}$ By ninth grade, only 41 percent remain to take geometry. Figure 3 shows this drop-off visually, with the acceleration discontinuity becoming smaller in eighth and ninth grades relative to its initial size in seventh grade. By tenth grade, only 24 percent of initially accelerated students remain to take Algebra II. By eleventh grade, only 14 percent are taking Precalculus. Figure 4 shows that the initial acceleration discontinuity has nearly vanished four years later, with a large gap at point in the skill distribution between the fraction of students enrolled in seventh grade Pre-Algebra and the fraction enrolled in eleventh grade Precalculus. ${ }^{16}$ Each year, roughly one third of students in the accelerated track drop back into the non-accelerated track the subsequent year. As the second and third rows of Table 5 show, most marginal students who remain in the accelerated track pass their courses but few earn As or Bs.

For the first two years, in middle school, acceleration substantially boosts the fraction of students enrolled in more rigorous math coursework and even seems to have positive impacts on grades in non-math courses, raising the probability of having a non-math GPA of at least a B by more than 30 percentage points. Though not shown here, that effect is divided roughly evenly across science and humanities courses, suggesting the relevant channel is not knowledge spillovers from math but something more general, such as peer effects or changed academic expectations.

By junior year of high school, the accumulated leakage from the pipeline means that seventh grade acceleration increases Precalculus taking rates by a statistically significant but modest 14 percentage points. ${ }^{17}$ The point estimates suggest that nearly all such students pass that Precalculus course, with acceleration increasing by a statistically significant nine percentage points the proportion of students earning at least a B in Precalculus by junior year. Acceleration thus increases the share of students on and succeeding in a college-ready track near the end of high school albeit at a lower rate than that induced by the acceleration in middle school. ${ }^{18}$

\footnotetext{
${ }^{15}$ Nearly all of those students take the Algebra I End-of-Course exam and 40 percent of those pass that exam, implying that acceleration does substantially increase the number of students qualifying as proficient in Algebra I by the end of 8th grade. Students at the EVAAS threshold were those predicted to have 70 percent pass rates on that exam, suggesting the marginal accelerated student here is under-performing those EVAAS predictions.

${ }^{16}$ Figure 4 shows that a small number, roughly six percent, of students in our sample appear to take Precalculus in 11th grade without having been accelerated in 7th grade. This appears to be due to three factors: students doubling up on coursework in some intervening year, students taking coursework out of the traditional sequence, or a few odd course titles that are challenging to categorize clearly in the traditional math sequence.

${ }^{17}$ The last row of Table 5 shows that persistence in WCPSS seems unaffected by seventh grade math acceleration. This is consistent with the fact that our choice to assign zeroes for outcomes to students missing from WCPSS data in later years leads to very similar point estimates if we exclude such students entirely.

${ }^{18}$ Table 5 tests whether initial acceleration changed the timing of taking a given course. Table A.3 estimates the impact of acceleration on the probability of taking various high school courses by the end of high school. Estimated impacts on Geometry and Algebra II course-taking are substantially smaller, likely because many students ineligible for initial acceleration nonetheless eventually take those courses, as can be seen in the high control means for those variables. The impact on taking or earning at least a B in Precalculus, though noisier than that in Table 5, has a similar
} 
This average impact masks substantial heterogeneity by student characteristics. Table 6 shows estimated impacts of acceleration on grades in the initial Pre-Algebra course and on subsequent years' enrollment in the accelerated track, broken out by student income, race and gender. In their initial seventh grade Pre-Algebra course, low income students accelerated because of the policy earn lower grades than their non-low income counterparts, with both lower rates of passing and of earning As or Bs. Perhaps because of this, the rate at which students stay in the accelerated track in subsequent years varies tremendously by income. By eighth grade only half of low income students remain in the track, compared to nearly 90 percent of non-low income students. That roughly 40 percentage point gap in persistence in the pipeline remains fairly constant through high school. By eleventh grade, over 40 percent of initially accelerated non-low income students remain in the track taking Precalculus, compared to 5 percent of low income students, the latter estimate of which is statistically indistinguishable from zero. Figure 5 shows this graphically, with a clear discontinuity in Precalculus enrollment visible for non-low income students but no apparent discontinuity for low income students. Interestingly, no such clear heterogeneity presents itself by race, though estimates for white and Asian students are particularly noisy due to a relatively weak first stage.

Splitting the sample by gender also reveals substantial heterogeneity. Female students pass their initial Pre-Algebra class at substantially higher rates (97 percent) than male students (82 percent). The fraction who continue on to take Algebra I in eighth grade looks quite similar but a much higher fraction of male students leave the accelerated track after 8th grade. By ninth grade, only 32 percent of initially accelerated male students are still on the accelerated track, compared to 53 percent of female students. By eleventh grade, acceleration has had no discernible impact on the share of male students enrolled in Precalculus but has raised the fraction of female students taking Precalculus by 34 percentage points. In short, of those accelerated in seventh grade, all male students drop out of the accelerated track by eleventh grade whereas one third of female students remain. Figure 6 shows this graphically, with a clear discontinuity in Precalculus enrollment visible for female students but nothing apparent for male students. ${ }^{19}$

Low income students see no increase in Precalculus enrollment, whereas non-low income students' enrollment rates rise by at least 40 percentage points. We observe no heterogeneity by race, with point estimates for black and Hispanic students generally quite similar to those for white and

magnitude, perhaps because by definition students have only one additional year to take it.

${ }^{19}$ Though we ultimately believe that pre-calculus course-taking by 11 th grade is the single most important measure of whether this intervention succeeded, we acknowledge that our number of outcomes may raise concerns about multiple hypothesis testing. However, results are not sensitive to imposing a very conservative Bonferroni correction for 30 hypotheses $(.05 / 30=0.00167)$. 
Asian students. Female Precalculus enrollment rates rise by over 30 percentage points, whereas the point estimates for males is small and statistically indistinguishable from zero. Middle school math acceleration increases the fraction of eleventh graders doing college preparatory math coursework, driven by large increases among non-low income and female students. ${ }^{20}$

\subsection{College Readiness}

The final outcome we explore is the PLAN exam taken at the end of tenth grade by all WCPSS students. This exam is designed to predict success on the ACT, which in turn is intended to measures students' college readiness. The PLAN consists of four sections covering math, science, English and reading, scores from which are combined into a composite score. We use the PLAN's nationally normed percentile versions of such scores. Students are also asked a variety of questions, including their intended plans after high school. Table 7 shows estimated impacts of initial acceleration on PLAN scores and post-high school intentions.

Middle school math acceleration appears to have increased students' composite PLAN scores by a statistically significant 13 percentiles. The reduced form version of this discontinuity is shown graphically in Figure 7, which highlights that students just below the eligibility threshold are scoring around 30th percentile in the national distribution. This overall score increase is not driven exclusively by improved performance on the PLAN's math section, where scores improve by a statistically insignificant 8 percentiles. Acceleration also has a substantial impact on students' college intentions. The fraction of students reporting that they intend to enroll in a four-year college upon graduation from high school increases by 25 percentage points, compared to a baseline rate of 61 percent. The estimate in column 3, which treats those failing to take the PLAN exam in WCPSS as missing, is nearly unchanged if instead such students are counted as not intending to enroll in four-year colleges, as shown in column 4. The graphical version of this result is shown in Figure 8.

Table A.5 shows that the magnitude of the impact on PLAN composite scores is somewhat sensitive to specification. Estimated impacts are, however, statistically significant across nearly all tested specifications, including those using the Imbens-Kalyanaraman optimal bandwidth. The estimated impact of acceleration on college intentions is quite robust to specification and the decision to include or exclude those who did not take the PLAN exam. Nearly all point estimates fall in the 20-30 percentage point range and are at least marginally statistically significant. Table A.6 shows

\footnotetext{
${ }^{20}$ These estimated impacts of initial acceleration on subsequent Precalculus course-taking rates are quite robust to a variety of specifications, as seen in Table A.4. Across such specifications, overall Precalculus enrollment rates rise by 14-25 percentage points, estimates that are all statistically significant.
} 
little evidence of heterogeneity in these PLAN score and college intention impacts by income, race or gender. Given substantial demographic differences in pipeline leakage by 10th grade, this may imply that such impacts on college orientation are driven by the initial acceleration in 7 th grade and resulting exposure to new curriculum and peers, rather than contemporaneous coursework.

\section{Conclusion}

Concerned both about the low number and demographic composition of students enrolling in college preparatory math coursework in middle and high school, WCPSS implemented a targeted policy based on prior test scores to enroll appropriately skilled middle school students in an accelerated math track. Encouragingly, the policy appears to have substantially increased the share of students successfully completing an Algebra I course in eighth grade, and course assignment has become more strongly related to prior achievement and less to income and race. Though the pipeline beyond middle school is fairly leaky, acceleration in seventh grade increases the marginal student's access to Precalculus in eleventh grade, and the increases are driven by female and nonlow income students.

These results raise three further questions. First, can and should the targeted acceleration policy be modified in order to reduce leakage from the math pipeline? Potential modifications include increasing the amount of additional academic support available to accelerated students or incorporating non-test score based measures in the assignment process to improve identification of students likely to succeed in accelerated coursework. A simple potential modification is to raise the eligibility threshold, which would reduce the rate of leakage as the marginal student would now have stronger academic skills. It would, however, reduce the number of students encouraged to enroll in accelerated coursework, some of whom we observe are able to succeed in such courses. This tension between access and the return to the marginal eligible student is highlighted in recent work by Cestau et al. (2015).

Second and relatedly, what can be learned from the fact that non-low income and female students were much more likely than their low income and male counterparts to persist in the more rigorous math track? Course grades suggest that, even conditional on prior test scores, non-low income and female students were outperforming their peers in their initial, accelerated math courses. One possibility is that such students were more likely to take advantage of the additional tutoring services offered by the district. Another is that these students have the family resources or personal characteristics that help them manage the increased course rigor to which the policy exposed them. Yet another, particularly with regard to females, is that absent a policy such as this, some students 
are likely to underestimate their own ability or have teachers who underestimate their ability to succeed in the advanced course trajectory. Isolating the reason for such heterogeneity might help districts design future policies in such as a way to maximize the number of students succeeding in the math pipeline.

Third and finally, what effect if any will this relatively early intervention have on students' longer-run outcomes, such as college enrollment, college major, college completion and labor market earnings? Research cited in the introduction to this paper suggests that high school math coursework can have a substantial impact on such outcomes. The targeted acceleration rule substantially increased the proportion of students enrolled in college preparatory math near the end of high school, as well as their college aspirations. It remains to be seen whether this will translate into subsequent educational and economic success. 


\section{References}

Adelman, C. (2006). The toolbox revisited: Paths to degree completion from high school through college. US Department of Education.

Allensworth, E., T. Nomi, N. Montgomery, and V. E. Lee (2009). College preparatory curriculum for all: Academic consequences of requiring algebra and english i for ninth graders in chicago. Educational Evaluation and Policy Analysis 31(4), 367-391.

Altonji, J. G. (1995). The effects of high school curriculum on education and labor market outcomes. The Journal of Human Resources 30(3), 409-438.

Altonji, J. G., E. Blom, and C. Meghir (2012). Heterogeneity in human capital investments: High school curriculum, college major, and careers. Annual Review of Economics 4(1), 185-223.

Angrist, J. D., G. W. Imbens, and D. B. Rubin (1996). Identification of causal effects using instrumental variables. Journal of the American statistical Association 91(434), 444-455.

Blank, R. M. (1991). The effects of double-blind versus single-blind reviewing: Experimental evidence from the american economic review. The American Economic Review, 1041-1067.

Brown, C. and M. Corcoran (1997). Sex-based differences in school content and the male/female wage gap. Journal of Labor Economics 15(3), 431-465.

Calonico, S., M. D. Cattaneo, and R. Titiunik (2014). Robust nonparametric confidence intervals for regression-discontinuity designs. Econometrica 82(6), 2295-2326.

Card, D. and L. Giuliano (2015, September). Can universal screening increase the representation of low income and minority students in gifted education? Working Paper 21519, National Bureau of Economic Research.

Cestau, D., D. Epple, and H. Sieg (2015, June). Admitting students to selective education programs: Merit, profiling, and affirmative action. Working Paper 21232, National Bureau of Economic Research.

Clotfelter, C. T., H. F. Ladd, and J. Vigdor (2005). Who teaches whom? race and the distribution of novice teachers. Economics of Education review 24(4), 377-392.

Clotfelter, C. T., H. F. Ladd, and J. L. Vigdor (2006). Teacher-student matching and the assessment of teacher effectiveness. Journal of Human Resources 41(4), 778-820.

Clotfelter, C. T., H. F. Ladd, and J. L. Vigdor (2015). The aftermath of accelerating algebra: Evidence from district policy initiatives. Journal of Human Resources 50(1), 159-188.

Conger, D., M. C. Long, and P. Iatarola (2009). Explaining race, poverty, and gender disparities in advanced course-taking. Journal of Policy Analysis and Management 28(4), 555-576. 
Cortes, K. E., J. S. Goodman, and T. Nomi (2015). Intensive math instruction and educational attainment: Long-run impacts of double-dose algebra. Journal of Human Resources 50(1), $108-158$.

Domina, T. (2014). The link between middle school mathematics course placement and achievement. Child development 85(5), 1948-1964.

Dougherty, S. M., J. S. Goodman, D. V. Hill, E. G. Litke, and L. C. Page (2015). Middle school math acceleration and equitable access to eighth-grade algebra evidence from the wake county public school system. Educational Evaluation and Policy Analysis 37(1 suppl), 80S-101S.

Gamoran, A. and E. C. Hannigan (2000). Algebra for everyone? benefits of college-preparatory mathematics for students with diverse abilities in early secondary school. Educational Evaluation and Policy Analysis 22(3), 241-254.

Gardner, D. P., Y. W. Larsen, W. Baker, et al. (1983). A nation at risk: The imperative for educational reform. Washington, DC: US Government Printing Office.

Goldin, C. and C. Rouse (2000). Orchestrating impartiality: The impact of" blind" auditions on female musicians. American Economic Review, 715-741.

Goodman, J. S. (2012). The labor of division: Returns to compulsory math coursework. (RWP12032).

Grissom, J. A. and C. Redding (2016). Discretion and disproportionality. AERA Open 2(1).

Grogger, J. and E. Eide (1995). Changes in college skills and the rise in the college wage premium. Journal of Human Resources, 280-310.

Hanushek, E. A. and L. Woessmann (2015). The knowledge capital of nations: Education and the economics of growth. Cambridge, MA: MIT Press.

Imbens, G. and K. Kalyanaraman (2012). Optimal bandwidth choice for the regression discontinuity estimator. The Review of economic studies 79(3), 933-959.

Imbens, G. W. and T. Lemieux (2008). Regression discontinuity designs: A guide to practice. Journal of econometrics 142(2), 615-635.

Jackson, C. K. (2009). Student demographics, teacher sorting, and teacher quality: Evidence from the end of school desegregation. Journal of Labor Economics 27(2), 213-256.

Jackson, C. K. (2010). A little now for a lot later a look at a texas advanced placement incentive program. Journal of Human Resources 45(3), 591-639.

Joensen, J. S. and H. S. Nielsen (2009). Is there a causal effect of high school math on labor market outcomes? Journal of Human Resources 44(1), 171-198. 
Kalogrides, D. and S. Loeb (2013). Different teachers, different peers the magnitude of student sorting within schools. Educational Researcher 42(6), 304-316.

Lazear, E. P. (2001). Educational production. The Quarterly Journal of Economics 116(3), 777803.

Lee, D. S. and D. Card (2008). Regression discontinuity inference with specification error. Journal of Econometrics 142(2), 655-674.

Levine, P. B. and D. J. Zimmerman (1995). The benefit of additional high-school math and science classes for young men and women. Journal of Business \& Economic Statistics 13(2), 137-149.

Liang, J.-H., P. E. Heckman, and J. Abedi (2012). What do the california standards test results reveal about the movement toward eighth-grade algebra for all? Educational Evaluation and Policy Analysis 34(3), 328-343.

Long, M. C., D. Conger, and P. Iatarola (2012). Effects of high school course-taking on secondary and postsecondary success. American Educational Research Journal 49(2), 285-322.

Loveless, T. (2008). The misplaced math student: Lost in eighth-grade algebra. Brown Center on Education Policy at Brookings.

Ludwig, J. and D. L. Miller (2007). Does Head Start improve children's life chances? Evidence from a regression discontinuity design. The Quarterly Journal of Economics, 159-208.

Nomi, T. (2012). The unintended consequences of an algebra-for-all policy on high-skill students effects on instructional organization and students academic outcomes. Educational Evaluation and Policy Analysis 34(4), 489-505.

Rose, H. (2004). Has curriculum closed the test score gap in math? Topics in Economic Analysis \& Policy 4(1).

Sass, T. R., J. Hannaway, Z. Xu, D. N. Figlio, and L. Feng (2012). Value added of teachers in high-poverty schools and lower poverty schools. Journal of Urban Economics 72(2), 104-122.

Schneider, M. (2009). Math in american high schools: The delusion of rigor. Education Outlook (10).

Silver, E. A. (1995). Rethinking algebra for all. Educational Leadership 52(6), 30-33.

Smith, J., M. Hurwitz, and C. Avery (2015, May). Giving college credit where it is due: Advanced placement exam scores and college outcomes. Working Paper 21147, National Bureau of Economic Research.

Smith, J. B. (1996). Does an extra year make any difference? the impact of early access to algebra on long-term gains in mathematics attainment. Educational Evaluation and Policy Analysis 18(2), 141-153. 
Stein, M. K., J. H. Kaufman, M. Sherman, and A. F. Hillen (2011). Algebra a challenge at the crossroads of policy and practice. Review of Educational Research 81(4), 453-492.

Tate, W. F. (1997). Race-ethnicity, ses, gender, and language proficiency trends in mathematics achievement: An update. Journal for Research in Mathematics Education, 652-679.

Weinberger, C. J. (1999). Mathematical college majors and the gender gap in wages. Industrial Relations: A Journal of Economy and Society 38(3), 407-413. 
Figure 1: Enrollment in Pre-Algebra in Seventh grade

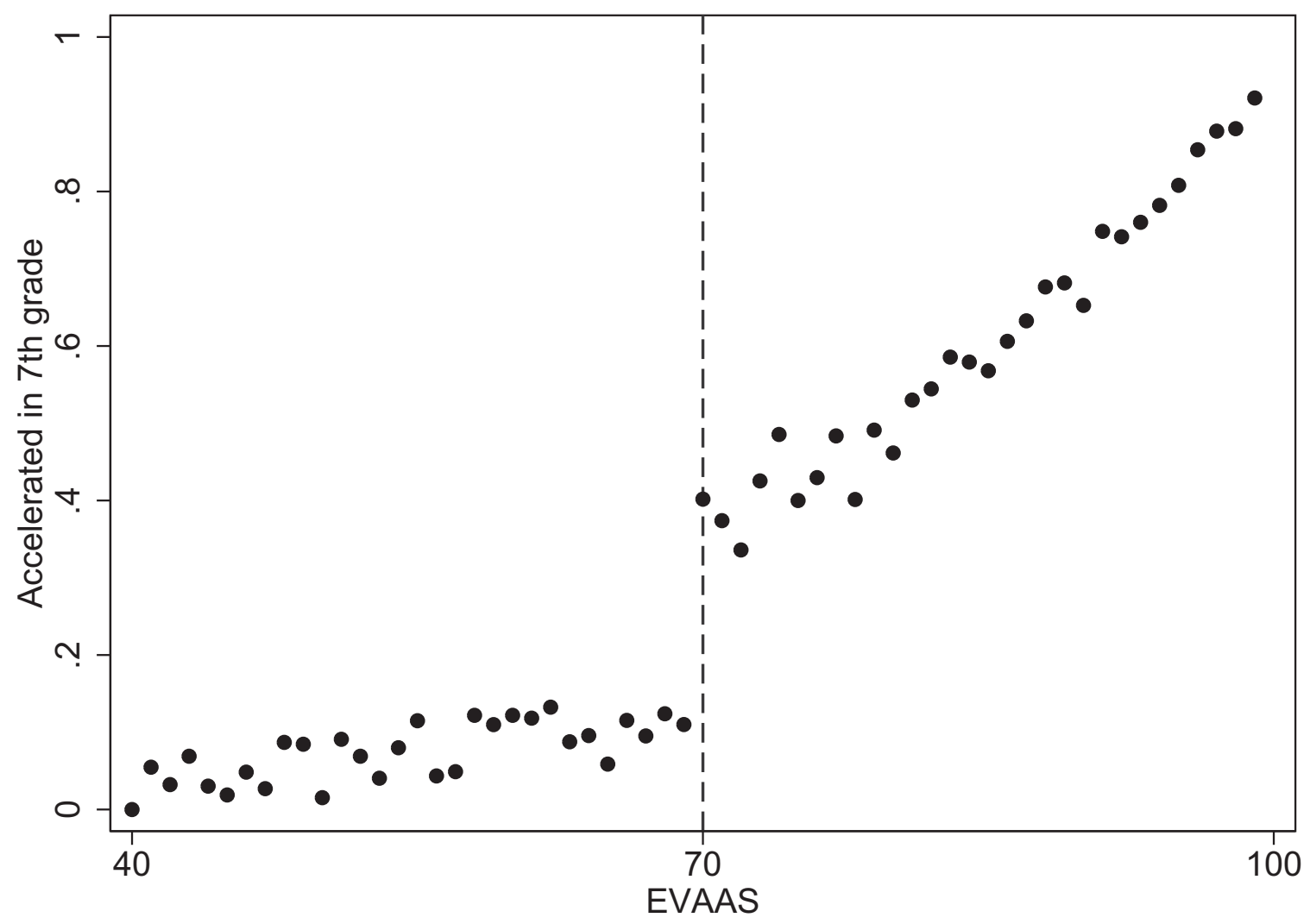

Notes: Shown above is the fraction of students who enrolled in Pre-Algebra by seventh grade, as a function of their maximum EVAAS score measured prior to seventh grade. EVAAS scores have been collapsed to one-point wide bins. 
Figure 2: Math Achievement

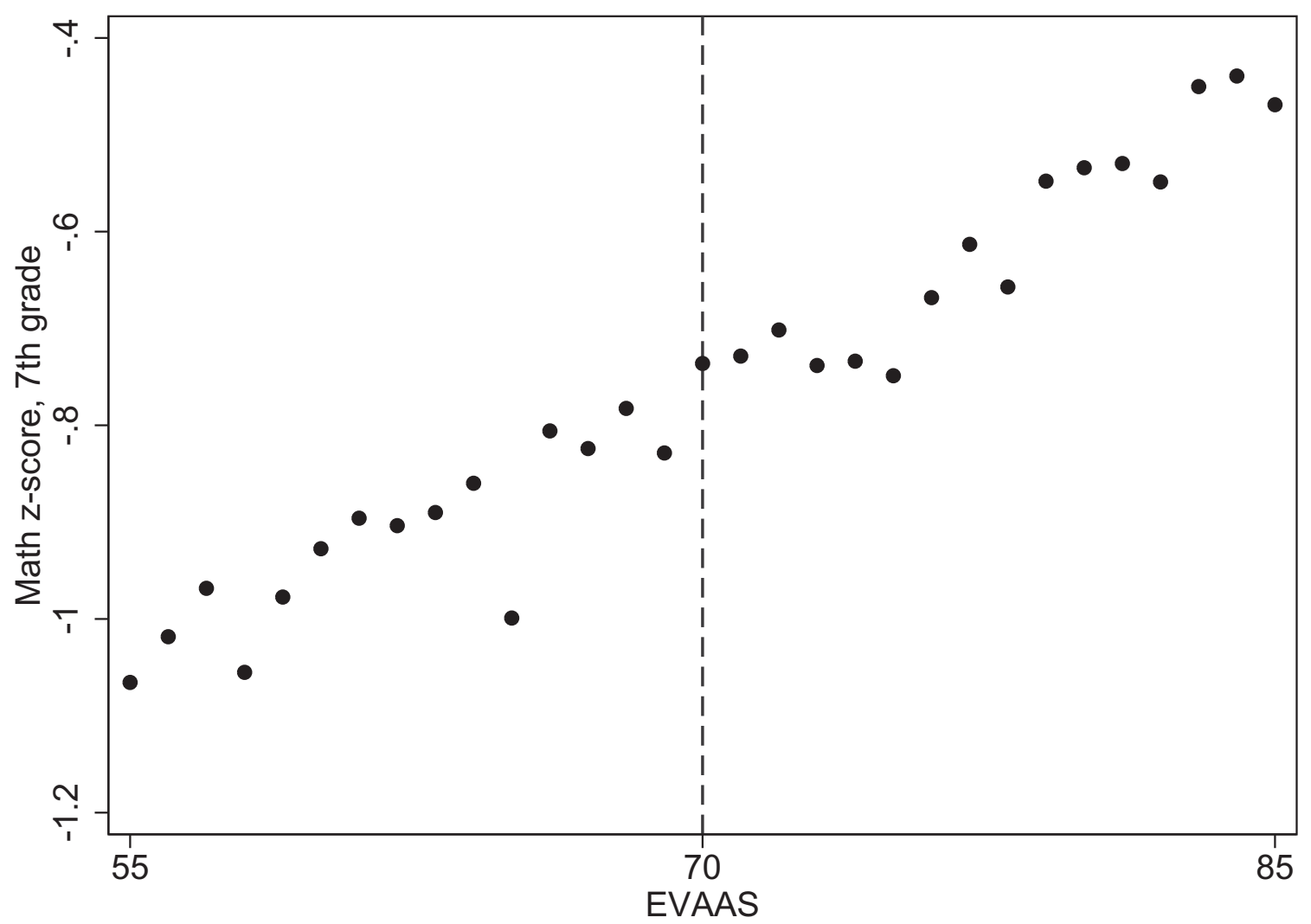

Notes: Shown above are students' mean z-scores (standardizedd by grade and year) on North Carolina's end of seventh grade math exam, as a function of their maximum EVAAS score measured prior to seventh grade. EVAAS scores have been collapsed to one-point wide bins. 
Figure 3: Pipeline Persistence, Years 2 and 3

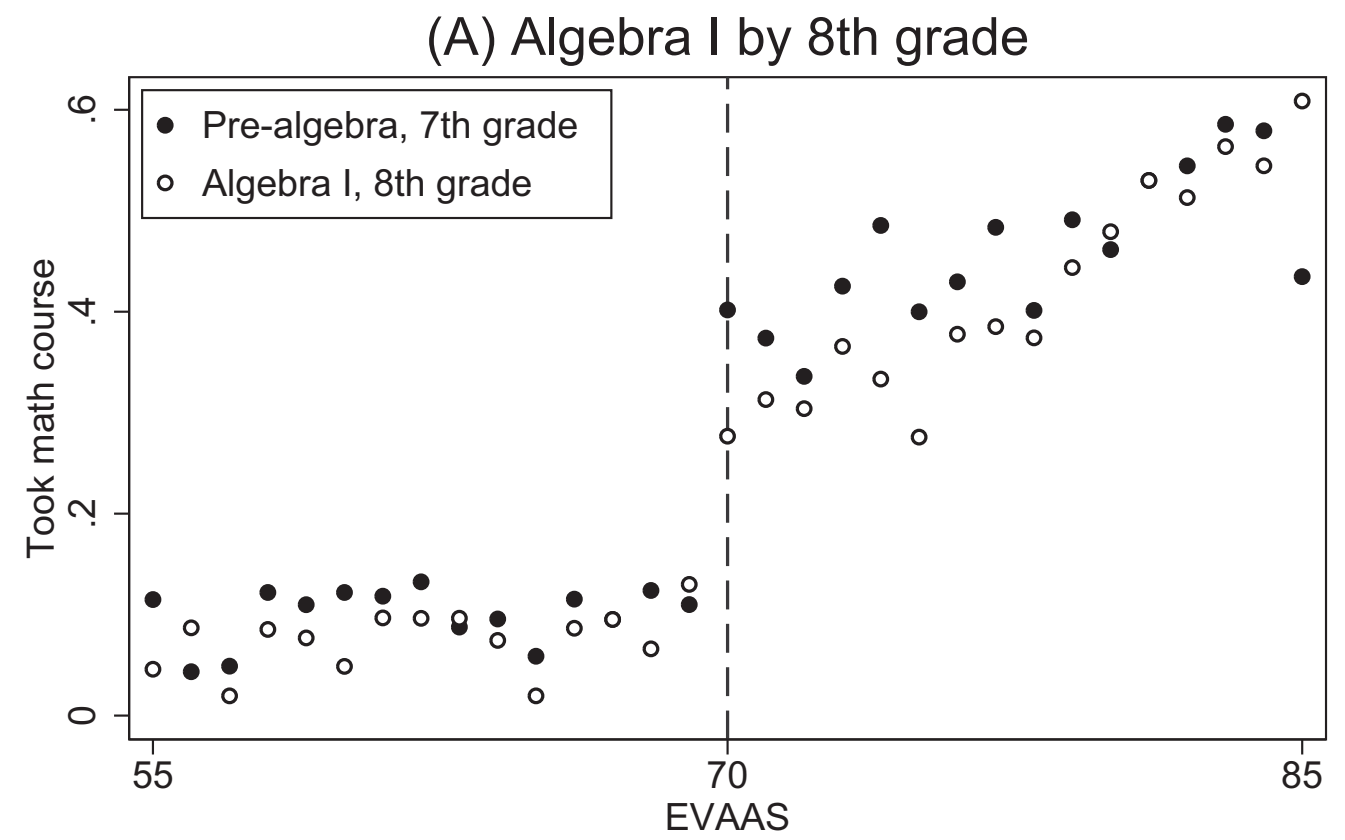

(B) Geometry by 9th grade

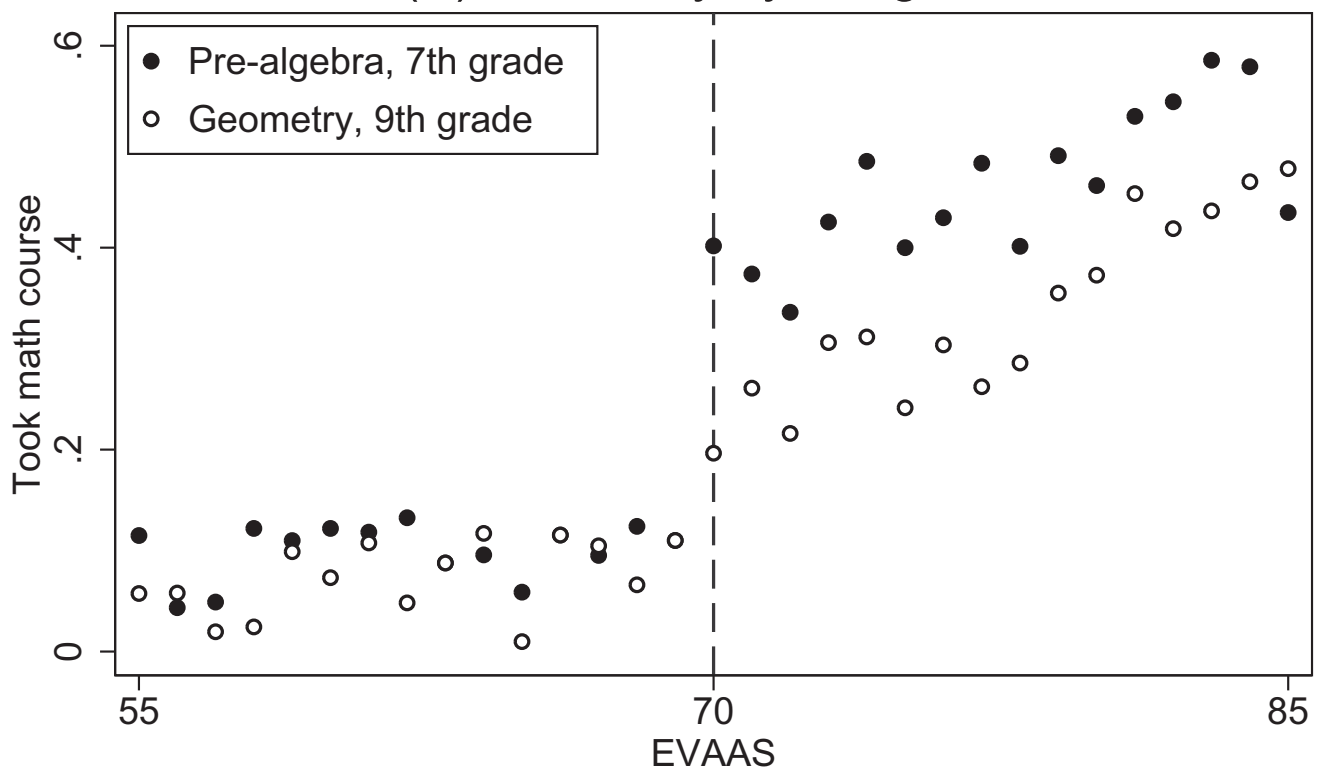

Notes: Shown above in panels A and B are respectively the fraction of students who enrolled in Algebra I by 8th grade and geometry by ninth grade, as a function of their maximum EVAAS score measured prior to seventh grade. EVAAS scores have been collapsed to one-point wide bins. In each panel, the open circles show as a reference point the fraction of students initially enrolled in Pre-Algebra in seventh grade. 
Figure 4: Pipeline Persistence, Years 4 and 5

(A) Algebra II by 10 th grade

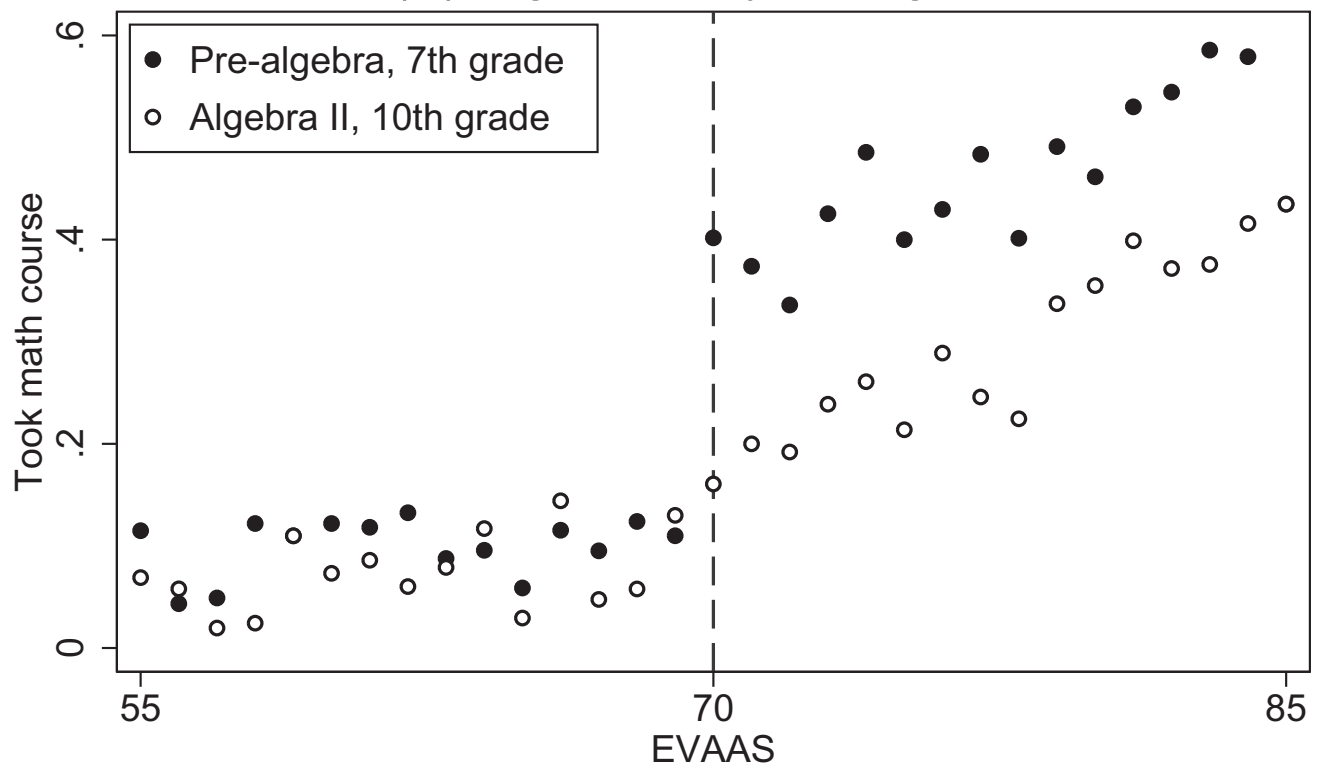

(B) Pre-calculus by 11 th grade

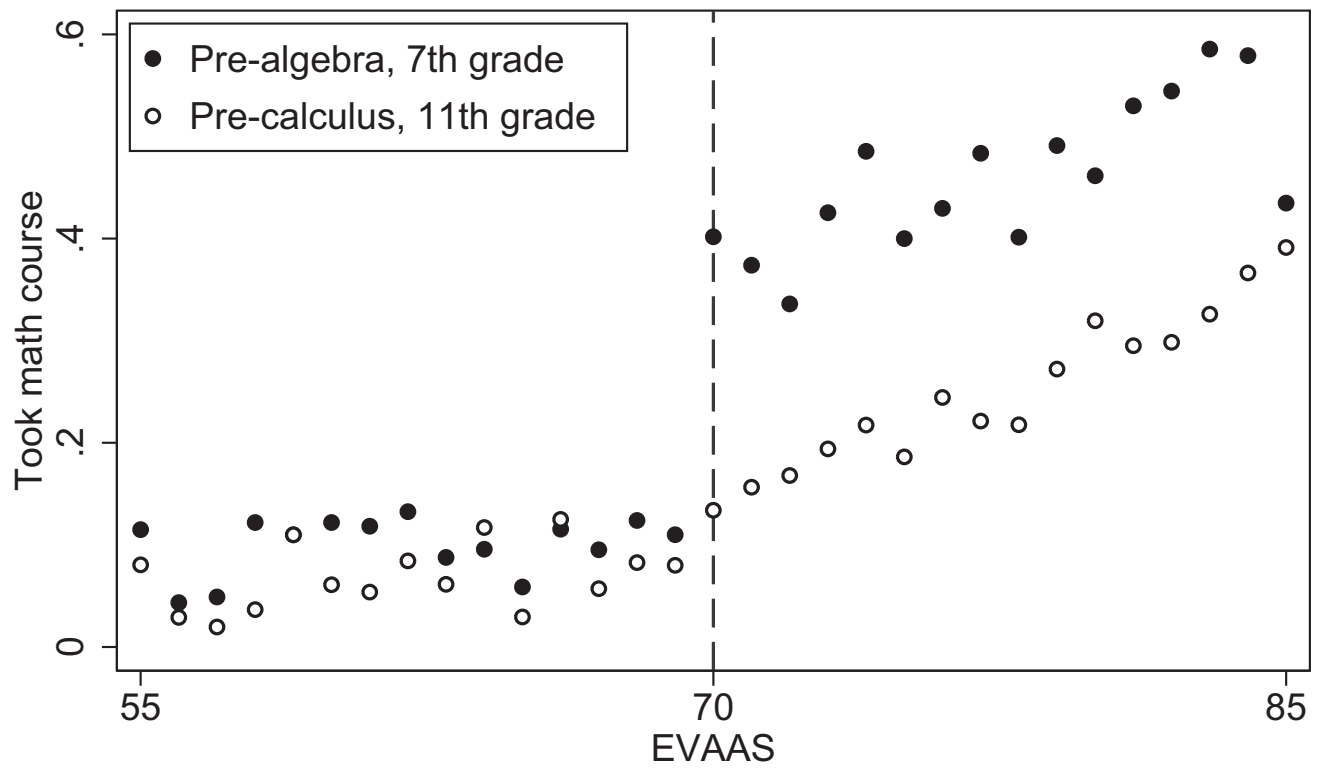

Notes: Shown above in panels A and B are respectively the fraction of students who enrolled in Algebra II by tenth grade and Precalculus by eleventh grade, as a function of their maximum EVAAS score measured prior to seventh grade. EVAAS scores have been collapsed to one-point wide bins. In each panel, the open circles show as a reference point the fraction of students initially enrolled in Pre-Algebra in seventh grade. 
Figure 5: Precalculus Enrollment by Income

(A) Non-low income students

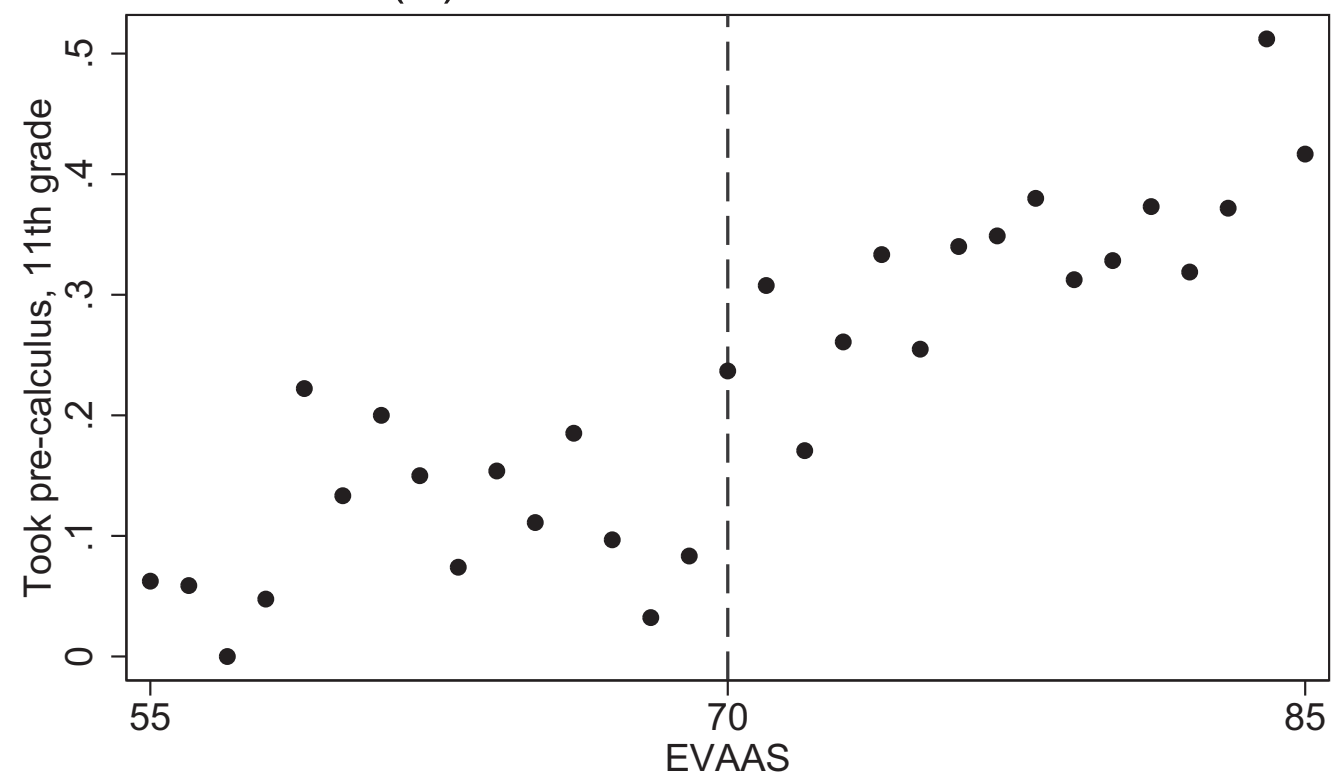

(B) Low income students

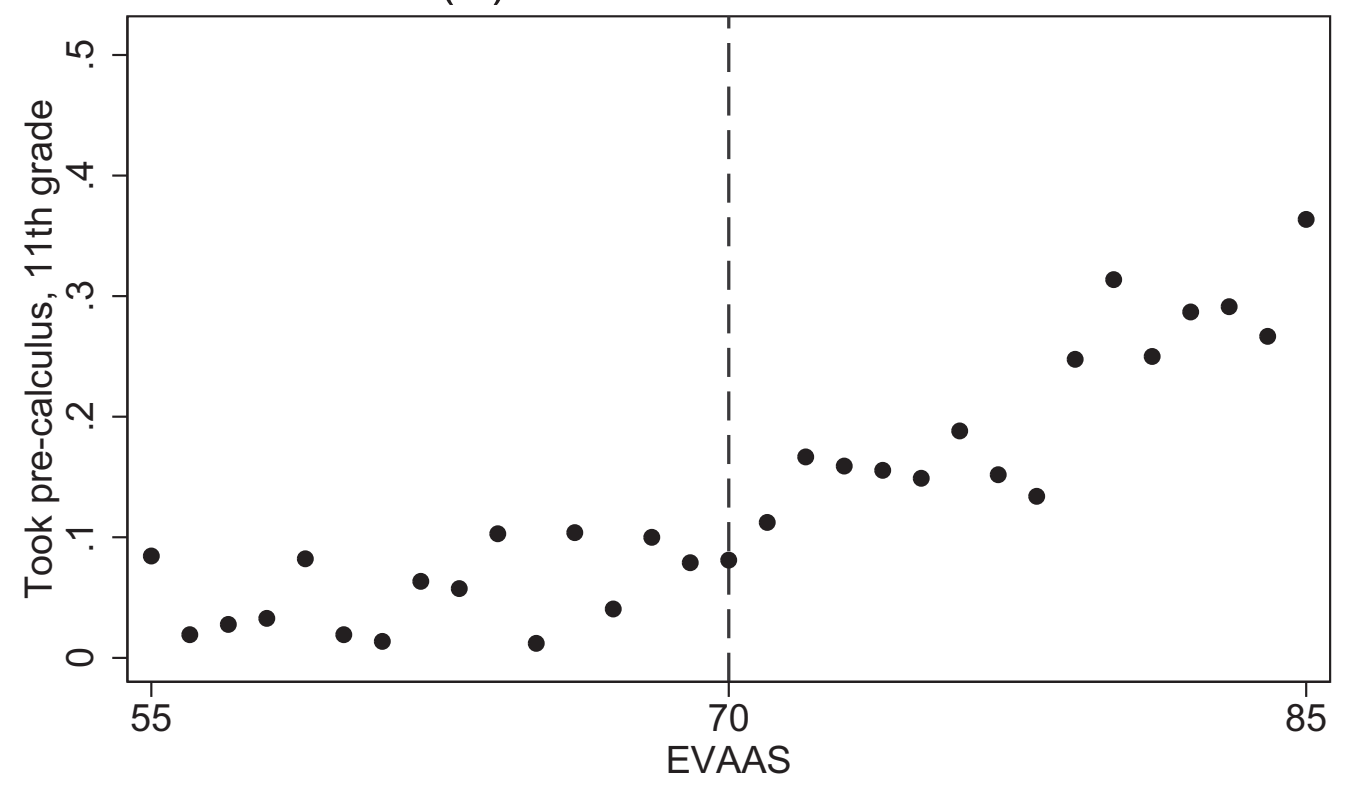

Notes: Shown above is the fraction of students who enrolled in Precalculus by eleventh grade, as a function of their maximum EVAAS score measured prior to seventh grade. EVAAS scores have been collapsed to one-point wide bins. Panels A and B respectively limit the sample to non-low income and low income students. 
Figure 6: Precalculus Enrollment by Gender

(A) Female students

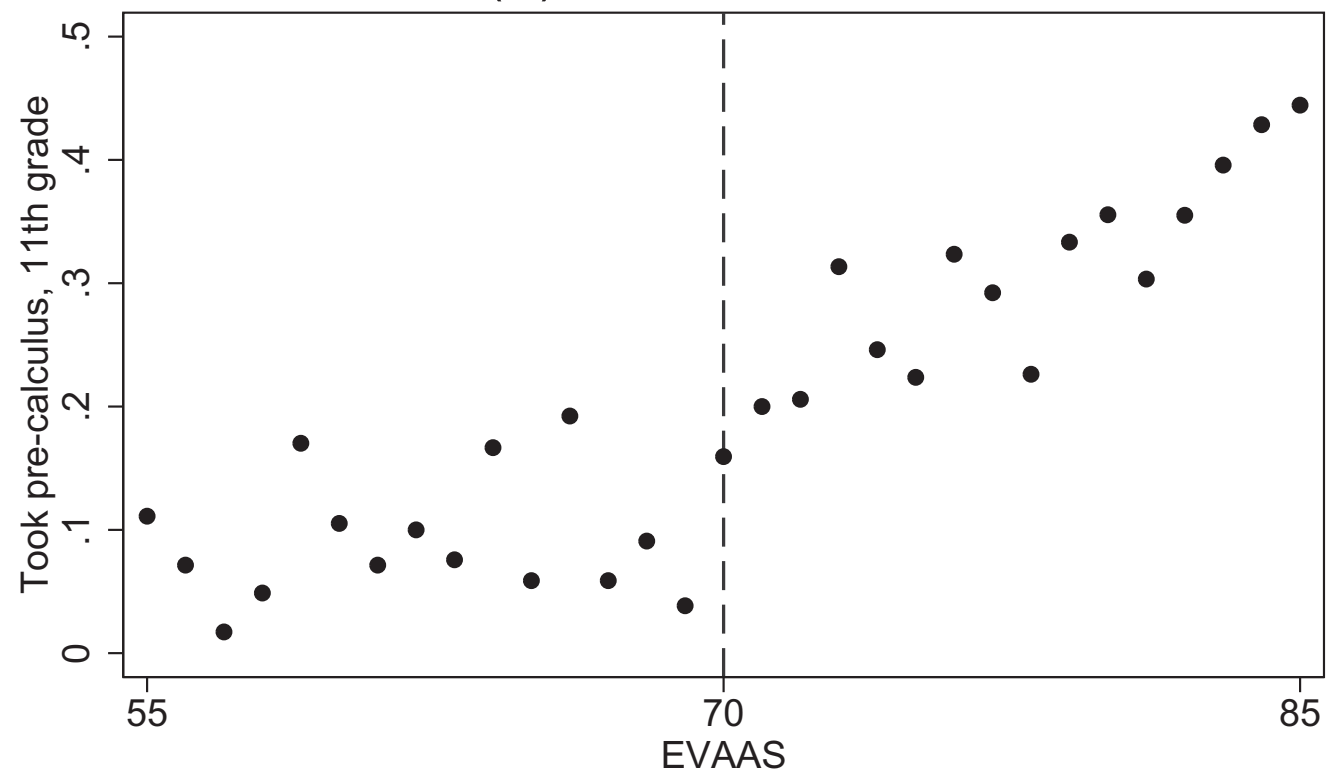

(B) Male students

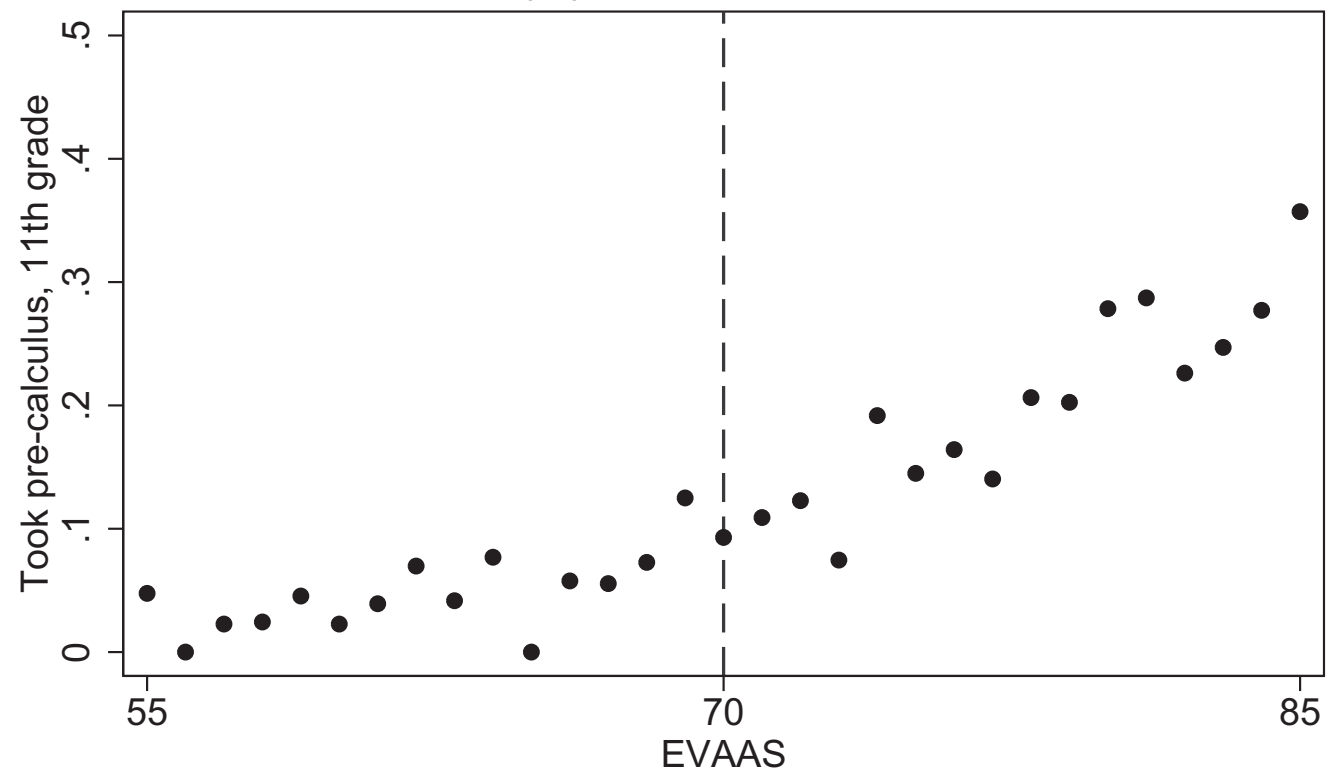

Notes: Shown above is the fraction of students who enrolled in Precalculus by eleventh grade, as a function of their maximum EVAAS score measured prior to seventh grade. EVAAS scores have been collapsed to one-point wide bins. Panels A and B respectively limit the sample to female and male students. 
Figure 7: College Readiness Percentile, tenth Grade PLAN Exam

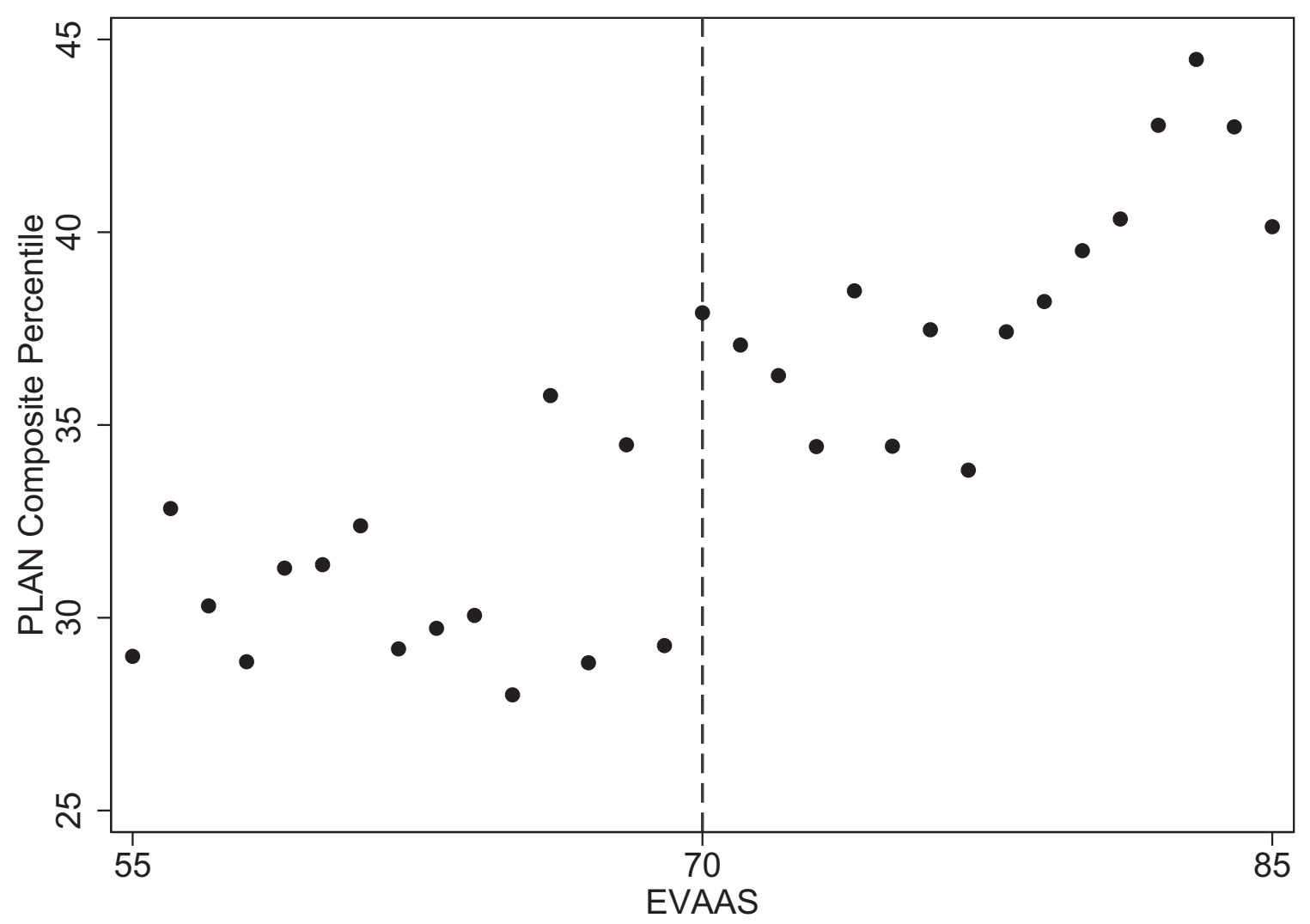

Notes: Shown above are students' mean composite scores on the tenth grade PLAN exam, as a function of their maximum EVAAS score measured prior to seventh grade. EVAAS scores have been collapsed to one-point wide bins. Scores are measured in percentiles normed to a national distribution. 
Figure 8: Plans to Attend Four-Year College

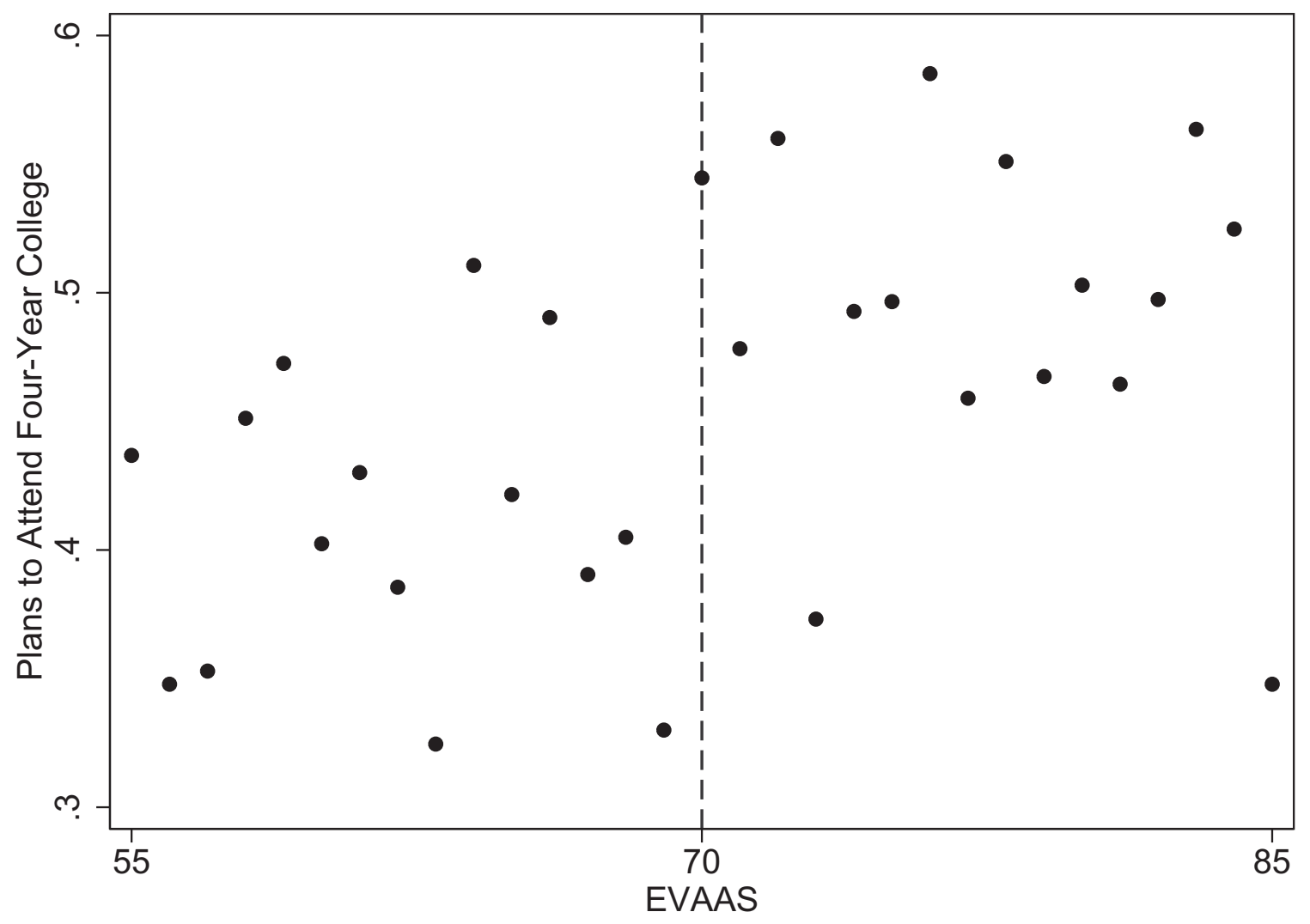

Notes: Shown above is the fraction of students who state on their tenth grade PLAN exam that they plan to attend four-year college, as a function of their maximum EVAAS score measured prior to seventh grade. EVAAS scores have been collapsed to one-point wide bins. Those who do not take the PLAN exam are counted as zeroes. 
Table 1: Summary Statistics

\begin{tabular}{|c|c|c|c|c|}
\hline & $\begin{array}{c}\text { (1) } \\
\text { All students }\end{array}$ & $\begin{array}{c}(2) \\
\text { Accelerated }\end{array}$ & $\begin{array}{c}(3) \\
\text { Non-accelerated }\end{array}$ & $\begin{array}{c}\text { (4) } \\
\text { RD sample }\end{array}$ \\
\hline \multicolumn{5}{|l|}{ (A) Demographics } \\
\hline Low income & 0.429 & 0.296 & 0.656 & 0.683 \\
\hline Black/Hispanic & 0.397 & 0.272 & 0.610 & 0.654 \\
\hline Female & 0.501 & 0.503 & 0.497 & 0.519 \\
\hline Special education & 0.460 & 0.515 & 0.366 & 0.248 \\
\hline Limited English proficiency & 0.154 & 0.127 & 0.199 & 0.212 \\
\hline \multicolumn{5}{|l|}{ (B) Math course and skills } \\
\hline EVAAS score & 83.6 & 95.1 & 62.9 & 72.3 \\
\hline EVAAS score $\geq 70$ & 0.793 & 0.982 & 0.451 & 0.618 \\
\hline Initially accelerated & 0.631 & 1.000 & 0.000 & 0.366 \\
\hline 5th grade math z-score & 0.008 & 0.449 & -0.812 & -0.736 \\
\hline \multicolumn{5}{|c|}{ (C) Math course peer composition } \\
\hline Mean 5th grade math z-score & 0.006 & 0.413 & -0.690 & -0.551 \\
\hline Class size & 24.1 & 26.1 & 20.8 & 21.7 \\
\hline Fraction low income & 0.418 & 0.305 & 0.613 & 0.598 \\
\hline Fraction black or Hispanic & 0.387 & 0.280 & 0.570 & 0.563 \\
\hline Fraction female & 0.497 & 0.502 & 0.487 & 0.501 \\
\hline \multicolumn{5}{|l|}{ (D) Outcomes } \\
\hline Math z-score, 7th grade & 0.022 & 0.445 & -0.799 & -0.724 \\
\hline Algebra I, 8th grade & 0.615 & 0.912 & 0.107 & 0.318 \\
\hline Precalculus, 11th grade & 0.447 & 0.663 & 0.078 & 0.200 \\
\hline PLAN percentile, 10 th grade & 60.7 & 70.4 & 33.9 & 36.0 \\
\hline Plans to attend 4-year college & 0.764 & 0.815 & 0.624 & 0.679 \\
\hline $\mathrm{N}$ & 20,800 & 13,131 & 7,669 & 3,333 \\
\hline
\end{tabular}

Notes: Mean values of key variables are shown for students in the 2011-12 cohorts. Column 1 includes all students. Columns 2 and 3 separate students into those enrolled and not enrolled in pre-algebra in seventh grade. Column 4 limits the sample to our main regression discontinuity sample, those within 15 EVAAS points of the eligibility threshold. 
Table 2: Eligibility and Initial Math Acceleration

\begin{tabular}{|c|c|c|c|c|c|c|}
\hline & $\begin{array}{c}\mathrm{BW}=10 \\
(1)\end{array}$ & $\begin{array}{c}\mathrm{BW}=15 \\
\text { (2) }\end{array}$ & $\begin{array}{c}\mathrm{BW}=15 \\
(3)\end{array}$ & $\begin{array}{c}\mathrm{BW}=20 \\
(4)\end{array}$ & $\begin{array}{c}\mathrm{BW}=\mathrm{IK} \\
(5)\end{array}$ & $\begin{array}{c}\mathrm{BW}=\mathrm{IK} \\
(6)\end{array}$ \\
\hline All students & $\begin{array}{c}0.281^{* * *} \\
(0.047)\end{array}$ & $\begin{array}{c}0.244^{* * *} \\
(0.034)\end{array}$ & $\begin{array}{c}0.240^{* * *} \\
(0.033)\end{array}$ & $\begin{array}{c}0.230^{* * *} \\
(0.031)\end{array}$ & $\begin{array}{c}0.224^{* * *} \\
(0.028)\end{array}$ & $\begin{array}{c}0.219^{* * *} \\
(0.027)\end{array}$ \\
\hline $\mathrm{F}$ & 35.2 & 51.9 & 53.6 & 54.5 & 62.4 & 66.5 \\
\hline $\mathrm{N}$ & 2,102 & 3,333 & 3,333 & 4,806 & 5,636 & 5,636 \\
\hline Low income & $\begin{array}{c}0.289^{* * *} \\
(0.053)\end{array}$ & $\begin{array}{c}0.235^{* * *} \\
(0.030)\end{array}$ & $\begin{array}{c}0.231^{* * *} \\
(0.030)\end{array}$ & $\begin{array}{c}0.223^{* * *} \\
(0.030)\end{array}$ & $\begin{array}{c}0.215^{* * *} \\
(0.026)\end{array}$ & $\begin{array}{c}0.213^{* * *} \\
(0.025)\end{array}$ \\
\hline $\mathrm{F}$ & 30.2 & 61.9 & 60.4 & 56.7 & 67.4 & 69.7 \\
\hline $\mathrm{N}$ & 1,463 & 2,271 & 2,271 & 3,113 & 4,462 & 4,462 \\
\hline Non-low income & $\begin{array}{c}0.274^{* * *} \\
(0.065)\end{array}$ & $\begin{array}{c}0.260^{* * *} \\
(0.060)\end{array}$ & $\begin{array}{c}0.271^{* * *} \\
(0.062)\end{array}$ & $\begin{array}{c}0.242^{* * *} \\
(0.060)\end{array}$ & $\begin{array}{c}0.189^{* * *} \\
(0.048)\end{array}$ & $\begin{array}{c}0.180^{* * *} \\
(0.047)\end{array}$ \\
\hline $\mathrm{F}$ & 17.6 & 18.8 & 19.3 & 16.5 & 15.8 & 14.5 \\
\hline $\mathrm{N}$ & 628 & 1,049 & 1,049 & 1,675 & 6,094 & 6,094 \\
\hline Black/Hispanic & $\begin{array}{c}0.337^{\text {*** }} \\
(0.054)\end{array}$ & $\begin{array}{c}0.279^{* * *} \\
(0.037)\end{array}$ & $\begin{array}{c}0.279^{* * *} \\
(0.036)\end{array}$ & $\begin{array}{c}0.245^{* * *} \\
(0.036)\end{array}$ & $\begin{array}{c}0.239^{* * *} \\
(0.034)\end{array}$ & $\begin{array}{c}0.235^{* * *} \\
(0.034)\end{array}$ \\
\hline $\mathrm{F}$ & 38.8 & 57.4 & 58.5 & 45.6 & 48.4 & 48.8 \\
\hline $\mathrm{N}$ & 1,411 & 2,180 & 2,180 & 2,979 & 5,777 & 5,777 \\
\hline White/Asian & $\begin{array}{c}0.157^{* *} \\
(0.069)\end{array}$ & $\begin{array}{c}0.171^{* * *} \\
(0.049)\end{array}$ & $\begin{array}{c}0.164^{* * *} \\
(0.048)\end{array}$ & $\begin{array}{c}0.200^{* * *} \\
(0.049)\end{array}$ & $\begin{array}{c}0.151^{* * *} \\
(0.034)\end{array}$ & $\begin{array}{c}0.149^{* * *} \\
(0.034)\end{array}$ \\
\hline $\mathrm{F}$ & 5.1 & 12.0 & 11.7 & 16.5 & 19.5 & 19.0 \\
\hline $\mathrm{N}$ & 592 & 989 & 989 & 1,597 & 3,363 & 3,363 \\
\hline Male & $\begin{array}{c}0.272^{* * *} \\
(0.056)\end{array}$ & $\begin{array}{c}0.245^{* * *} \\
(0.039)\end{array}$ & $\begin{array}{c}0.241^{\text {*** }} \\
(0.039)\end{array}$ & $\begin{array}{c}0.222^{* * *} \\
(0.037)\end{array}$ & $\begin{array}{c}0.212^{* * *} \\
(0.034)\end{array}$ & $\begin{array}{c}0.210^{* * *} \\
(0.033)\end{array}$ \\
\hline $\mathrm{F}$ & 23.7 & 39.6 & 37.9 & 34.9 & 39.4 & 39.3 \\
\hline $\mathrm{N}$ & 1,009 & 1,592 & 1,592 & 2,301 & 2,917 & 2,917 \\
\hline Female & $\begin{array}{c}0.304^{* * *} \\
(0.060)\end{array}$ & $\begin{array}{c}0.247^{* * *} \\
(0.042)\end{array}$ & $\begin{array}{c}0.253^{* * *} \\
(0.042)\end{array}$ & $\begin{array}{c}0.241^{* * *} \\
(0.037)\end{array}$ & $\begin{array}{c}0.224^{* * *} \\
(0.031)\end{array}$ & $\begin{array}{c}0.225^{* * *} \\
(0.030)\end{array}$ \\
\hline $\mathrm{F}$ & 25.7 & 34.0 & 36.3 & 42.0 & 53.3 & 55.6 \\
\hline $\mathrm{N}$ & 1,082 & 1,724 & 1,724 & 2,482 & 4,720 & 4,720 \\
\hline Controls & $\mathrm{N}$ & $\mathrm{N}$ & $\mathrm{Y}$ & $\mathrm{N}$ & $\mathrm{N}$ & $\mathrm{Y}$ \\
\hline
\end{tabular}

Notes: Heteroskedasticity robust standard errors clustered by initial middle school are in parentheses $(* \mathrm{p}<.10$ $* * \mathrm{p}<.05 * * * \mathrm{p}<.01$ ). First stage estimates show the impact of initial eligibility on the probability of enrollment in seventh grade accelerated math coursework. The coefficients shown are generated by local linear regression using the listed bandwidth and including cohort-by-middle school fixed effects. Columns 3 and 6 also include demographic controls. The Imbens-Kalyanaraman opt tha 3 al bandwidth takes values (in descending order of the panels) of 22.4, 26.5, 29.6, 30.6, 27.2, 23.6 and 28.3. Below each coefficient is the the F-statistic associated with the eligibility instrument. The proportion of students just below the mean who enroll in accelerated coursework is between 0.12 and 0.14 in all rows. 
Table 3: Math Classroom Peer and Teacher Characteristics

\begin{tabular}{|c|c|c|c|c|c|}
\hline & (1) & (2) & (3) & (4) & $(5)$ \\
\hline (A) Peers & $\begin{array}{c}\text { Mean } \\
\text { math skill }\end{array}$ & $\begin{array}{l}\text { St. dev. } \\
\text { math skill }\end{array}$ & $\begin{array}{l}\text { Class } \\
\text { size }\end{array}$ & $\begin{array}{c}\text { Fraction } \\
\text { black/Hisp. }\end{array}$ & $\begin{array}{c}\text { Fraction } \\
\text { female }\end{array}$ \\
\hline Accelerated & $\begin{array}{c}0.819^{* * *} \\
(0.157)\end{array}$ & $\begin{array}{l}-0.028 \\
(0.047)\end{array}$ & $\begin{array}{c}4.780^{* * *} \\
(1.482)\end{array}$ & $\begin{array}{c}-0.187^{* *} \\
(0.073)\end{array}$ & $\begin{array}{l}-0.006 \\
(0.038)\end{array}$ \\
\hline Mean of the Outcome & -0.77 & 0.65 & 20.31 & 0.61 & 0.50 \\
\hline $\mathrm{N}$ & 3,333 & 3,333 & 3,333 & 3,333 & 3,333 \\
\hline (B) Teacher & $\begin{array}{l}\text { Value- } \\
\text { added }\end{array}$ & $\begin{array}{l}\text { Low } \\
\text { VAM }\end{array}$ & $\begin{array}{c}\text { Years of } \\
\text { experience }\end{array}$ & $\begin{array}{l}\text { Black/ } \\
\text { Hispanic }\end{array}$ & Female \\
\hline Accelerated & $\begin{array}{c}0.096 \\
(0.294)\end{array}$ & $\begin{array}{l}-0.148^{*} \\
(0.082)\end{array}$ & $\begin{array}{c}3.253 \\
(2.400)\end{array}$ & $\begin{array}{c}0.075 \\
(0.094)\end{array}$ & $\begin{array}{c}0.084 \\
(0.149)\end{array}$ \\
\hline Mean of the Outcome & -0.11 & 0.26 & -11.04 & 0.22 & 0.78 \\
\hline $\mathrm{N}$ & 3,125 & 3,125 & 3,086 & 3,086 & 3,086 \\
\hline
\end{tabular}

Notes: Heteroskedasticity robust standard errors clustered by initial middle school are in parentheses $(* \mathrm{p}<.10 * *$ $\mathrm{p}<.05 * * * \mathrm{p}<.01)$. Instrumental variables estimates show the impact of initial math acceleration on the peer and teacher characteristics for each student's initial math classroom, where acceleration is instrumented with eligibility. The coefficients shown are generated by local linear regression using a bandwidth of 15 and including cohort-bymiddle school fixed effects. Below each coefficient is the mean of the outcome variable for students just below the threshold. In panel B, is an indicator for having a math teacher whose VAM does not meet "expected growth." 
Table 4: Math Acceleration and Standardized Test Scores

\begin{tabular}{|c|c|c|c|c|}
\hline & $\begin{array}{c}\text { Math } \\
\text { z-score } \\
\text { (1) }\end{array}$ & $\begin{array}{l}\text { 11-12 Coh } \\
\text { Took } \\
\text { math test } \\
\text { (2) }\end{array}$ & $\begin{array}{c}\text { Reading } \\
\text { Z-score } \\
\text { (3) }\end{array}$ & $\begin{array}{c}\text { 2011-13 Cohorts } \\
\text { Math } \\
\text { z-score } \\
(4)\end{array}$ \\
\hline After initial year & $\begin{array}{l}-0.038 \\
(0.156)\end{array}$ & $\begin{array}{c}0.043 \\
(0.031)\end{array}$ & $\begin{array}{l}-0.094 \\
(0.215)\end{array}$ & $\begin{array}{c}0.042 \\
(0.092)\end{array}$ \\
\hline Mean of the Outcome & -0.81 & 0.98 & -0.69 & -0.83 \\
\hline $\mathrm{N}$ & 3,307 & 3,333 & 3,290 & 5,232 \\
\hline After second year & $\begin{array}{c}0.007 \\
(0.159)\end{array}$ & $\begin{array}{c}0.058 \\
(0.048)\end{array}$ & $\begin{array}{c}0.178 \\
(0.192)\end{array}$ & $\begin{array}{c}0.071 \\
(0.078)\end{array}$ \\
\hline $\begin{array}{l}\text { Mean of the Outcome } \\
\mathrm{N}\end{array}$ & $\begin{array}{l}-0.80 \\
3,204\end{array}$ & $\begin{array}{c}0.95 \\
3,333\end{array}$ & $\begin{array}{l}-0.76 \\
3,191\end{array}$ & $\begin{array}{l}-0.80 \\
4,989\end{array}$ \\
\hline
\end{tabular}

Notes: Heteroskedasticity robust standard errors clustered by initial middle school are in parentheses $(* \mathrm{p}<.10 * *$ $\mathrm{p}<.05 * * * \mathrm{p}<.01)$. Instrumental variables estimates show the impact of initial math acceleration on standardized test scores, where acceleration is instrumented with eligibility. The coefficients shown are generated by local linear regression using a bandwidth of 15 and including cohort-by-middle school fixed effects. Columns 1 and 4 use as outcomes end-of-grade math test z-scores, standardized within grade and year. Column 2 uses indicators for taking those math exams. Column 3 uses end-of-grade reading test $\mathrm{z}$-scores, standardized within grade and year. The first row measures outcomes at the end of the first year of acceleration, which is seventh grade for the 2011-12 cohorts and sixth grade for the 2013 cohort. The second row measures outcomes at the end of the second year after acceleration, which is eighth grade for the 2011-12 cohorts and seventh grade for the 2013 cohort. Columns 1-3 include only the 2011-12 cohorts, while column 4 also includes the 2013 cohort. Below each coefficient is the mean of the outcome variable for students just below the threshold. 
Table 5: Math Acceleration and Course Grades

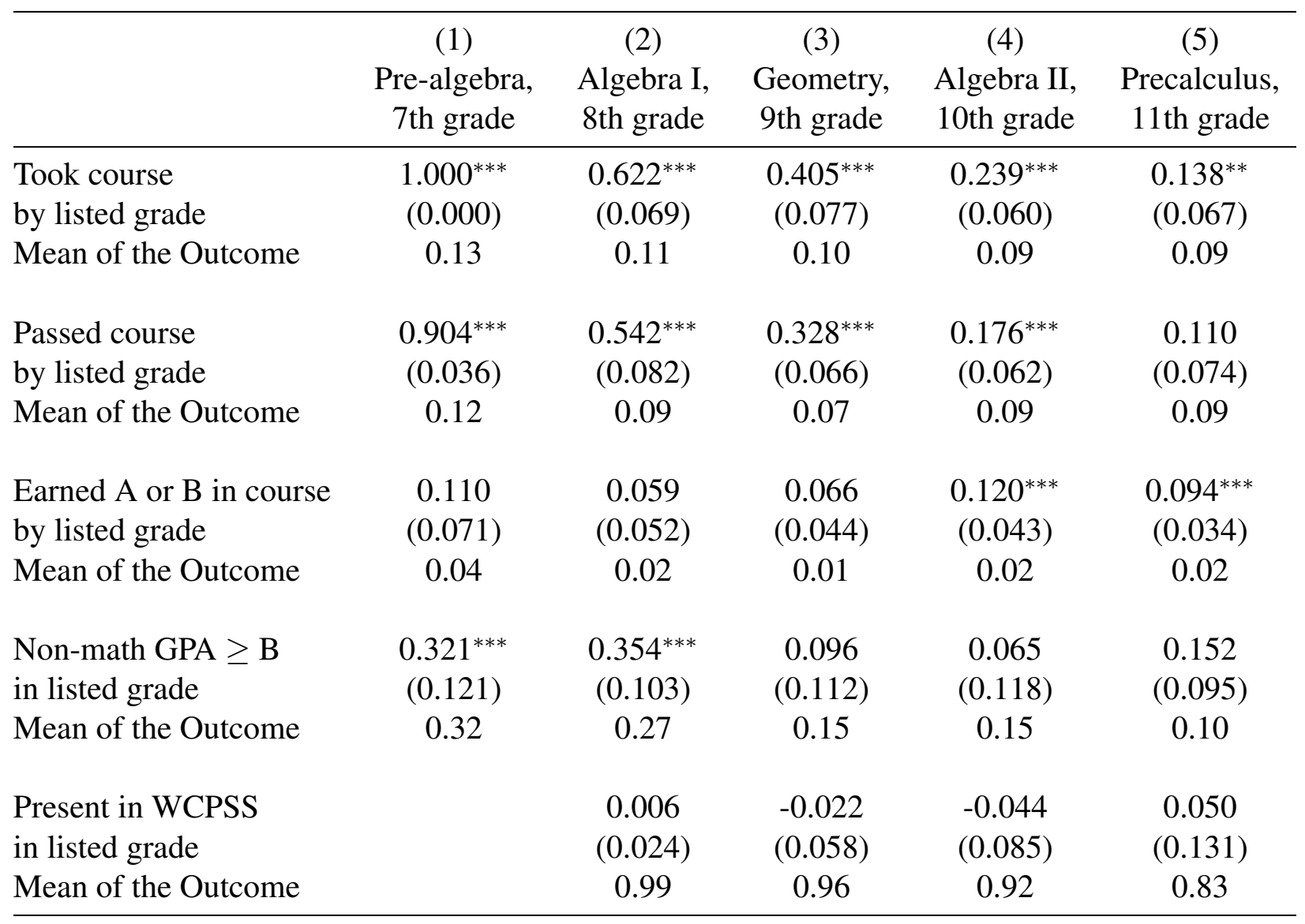

Notes: Heteroskedasticity robust standard errors clustered by initial middle school are in parentheses $(* \mathrm{p}<.10 * *$ $\mathrm{p}<.05 * * * \mathrm{p}<.01)$. Instrumental variables estimates show the impact of initial math acceleration on coursework outcomes, where acceleration is instrumented with eligibility. The coefficients shown are generated by local linear regression using a bandwidth of 15 and including cohort-by-middle school fixed effects. Panel A uses as outcomes indicators for being on the accelerated math track, as measured by having taken the listed course by the listed grade. Panel B uses indicators for passing that course, while panel C uses indicators for earning an A or B in that course. Panels D and E respectively use indicators for taking and passing by 8th grade the North Carolina end-of-course Algebra I exam. Panel F uses indicators for being present in WCPSS, as measured by any course enrollment. Below each coefficient is the mean of the outcome variable for students just below the threshold. The sample size in each regression is 3,333 . 
Table 6: Heterogeneous Effects on Math Coursework

\begin{tabular}{|c|c|c|c|c|c|c|}
\hline & $\begin{array}{c}\text { (1) } \\
\text { Passed } \\
\text { Pre-algebra, } \\
\text { 7th grade }\end{array}$ & $\begin{array}{c}\quad(2) \\
\text { A or B in } \\
\text { Pre-algebra, } \\
7 \text { th grade }\end{array}$ & $\begin{array}{c}(3) \\
\text { Took } \\
\text { Algebra I, } \\
\text { 8th grade }\end{array}$ & $\begin{array}{c}\text { (4) } \\
\text { Took } \\
\text { Geometry, } \\
\text { 9th grade }\end{array}$ & $\begin{array}{c}(5) \\
\text { Took } \\
\text { Algebra II, } \\
\text { 10th grade }\end{array}$ & $\begin{array}{c}\text { (6) } \\
\text { Took } \\
\text { Precalculus, } \\
\text { 11th grade }\end{array}$ \\
\hline Low income & $\begin{array}{c}0.888^{* * *} \\
(0.056)\end{array}$ & $\begin{array}{c}0.102 \\
(0.086)\end{array}$ & $\begin{array}{c}0.498^{* * *} \\
(0.096)\end{array}$ & $\begin{array}{c}0.340^{* * *} \\
(0.098)\end{array}$ & $\begin{array}{c}0.143^{*} \\
(0.077)\end{array}$ & $\begin{array}{c}0.045 \\
(0.088)\end{array}$ \\
\hline Mean of the Outcome & 0.12 & 0.05 & 0.11 & 0.10 & 0.10 & 0.09 \\
\hline $\mathrm{N}$ & 2,271 & 2,271 & 2,271 & 2,271 & 2,271 & 2,271 \\
\hline Non-low income & $\begin{array}{c}1.000^{* * *} \\
(0.032)\end{array}$ & $\begin{array}{c}0.266^{* * *} \\
(0.078)\end{array}$ & $\begin{array}{c}0.889^{* * *} \\
(0.172)\end{array}$ & $\begin{array}{c}0.641^{* * *} \\
(0.170)\end{array}$ & $\begin{array}{c}0.521^{* * *} \\
(0.141)\end{array}$ & $\begin{array}{c}0.414^{* * *} \\
(0.153)\end{array}$ \\
\hline Mean of the Outcome & 0.11 & 0.03 & 0.10 & 0.10 & 0.07 & 0.08 \\
\hline $\mathrm{N}$ & 1,049 & 1,049 & 1,049 & 1,049 & 1,049 & 1,049 \\
\hline Black/Hispanic & $\begin{array}{c}0.875^{* * *} \\
(0.048)\end{array}$ & $\begin{array}{c}0.137 \\
(0.089)\end{array}$ & $\begin{array}{c}0.542^{* * *} \\
(0.086)\end{array}$ & $\begin{array}{c}0.368^{* * *} \\
(0.097)\end{array}$ & $\begin{array}{c}0.248^{* * *} \\
(0.079)\end{array}$ & $\begin{array}{c}0.146^{*} \\
(0.086)\end{array}$ \\
\hline Mean of the Outcome & 0.13 & 0.04 & 0.11 & 0.10 & 0.08 & 0.09 \\
\hline $\mathrm{N}$ & 2,180 & 2,180 & 2,180 & 2,180 & 2,180 & 2,180 \\
\hline White/Asian & $\begin{array}{c}0.937^{* * *} \\
(0.096)\end{array}$ & $\begin{array}{c}-0.003 \\
(0.201)\end{array}$ & $\begin{array}{c}0.700^{* * *} \\
(0.257)\end{array}$ & $\begin{array}{c}0.262 \\
(0.296)\end{array}$ & $\begin{array}{c}0.083 \\
(0.248)\end{array}$ & $\begin{array}{c}0.041 \\
(0.305)\end{array}$ \\
\hline Mean of the Outcome & 0.11 & 0.04 & 0.13 & 0.13 & 0.11 & 0.09 \\
\hline $\mathrm{N}$ & 989 & 989 & 989 & 989 & 989 & 989 \\
\hline Male & $\begin{array}{c}0.823^{* * *} \\
(0.073)\end{array}$ & $\begin{array}{c}0.137 \\
(0.090)\end{array}$ & $\begin{array}{c}0.603^{* * *} \\
(0.141)\end{array}$ & $\begin{array}{l}0.319^{* *} \\
(0.137)\end{array}$ & $\begin{array}{c}0.196^{*} \\
(0.112)\end{array}$ & $\begin{array}{l}-0.055 \\
(0.101)\end{array}$ \\
\hline Mean of the Outcome & 0.12 & 0.02 & 0.12 & 0.11 & 0.10 & 0.09 \\
\hline $\mathrm{N}$ & 1,592 & 1,592 & 1,592 & 1,592 & 1,592 & 1,592 \\
\hline Female & $\begin{array}{c}0.969^{* * *} \\
(0.046)\end{array}$ & $\begin{array}{c}0.111 \\
(0.121)\end{array}$ & $\begin{array}{c}0.664^{* * *} \\
(0.108)\end{array}$ & $\begin{array}{c}0.527^{* * *} \\
(0.124)\end{array}$ & $\begin{array}{c}0.306^{* * *} \\
(0.112)\end{array}$ & $\begin{array}{c}0.336^{* * *} \\
(0.100)\end{array}$ \\
\hline Mean of the Outcome & 0.12 & 0.06 & 0.10 & 0.10 & 0.08 & 0.08 \\
\hline $\mathrm{N}$ & 1,724 & 1,724 & 1,724 & 1,724 & 1,724 & 1,724 \\
\hline
\end{tabular}

Notes: Heteroskedasticity robust standard errors clustered by initial middle school are in parentheses $(* \mathrm{p}<.10$ $* * \mathrm{p}<.05 * * * \mathrm{p}<.01)$. Instrumental variables estimates show the impact of initial math acceleration on the listed outcomes, where acceleration is instrumented with eligibility. The coefficients shown are generated by local linear regression using a bandwidth of 15 and including cohort-by-middle school fixed effects. Below each coefficient is the mean of the outcome variable for students just below the threshold. 
Table 7: College Readiness Scores and Enrollment Plans

\begin{tabular}{lccccc}
\hline & $(1)$ & $(2)$ & $(3)$ & $(4)$ & $(5)$ \\
& $\begin{array}{c}\text { PLAN } \\
\text { composite } \\
\text { percentile }\end{array}$ & $\begin{array}{c}\text { PLAN } \\
\text { math } \\
\text { percentile }\end{array}$ & $\begin{array}{c}\text { Plans for } \\
\text { four-year } \\
\text { college }\end{array}$ & $\begin{array}{c}\text { Plans for } \\
\text { four-year } \\
\text { college }\end{array}$ & $\begin{array}{c}\text { Took } \\
\text { PLAN } \\
\text { exam }\end{array}$ \\
\hline All students & $13.091^{* *}$ & 7.798 & $0.251^{* *}$ & $0.288^{* *}$ & 0.124 \\
Mean of the Outcome & $(6.475)$ & $(6.968)$ & $(0.122)$ & $(0.134)$ & $(0.128)$ \\
& 31.09 & 30.89 & 0.61 & 0.43 & 0.70 \\
$\mathrm{~N}$ & 2,480 & 2,491 & 2,494 & 3,333 & 3,333 \\
\hline
\end{tabular}

Notes: Heteroskedasticity robust standard errors clustered by initial middle school are in parentheses $(* \mathrm{p}<.10$ $* * \mathrm{p}<.05 * * * \mathrm{p}<.01)$. Instrumental variables estimates show the impact of initial math acceleration on the listed outcome on the tenth grade PLAN exam, where acceleration is instrumented with eligibility. The coefficients shown are generated by local linear regression using a bandwidth of 15 and including cohort-by-middle school fixed effects. Outcomes in the first two columns are nationally normed percentile scores on the overall PLAN exam and its math component. The third column indicates whether a student intends to attend a four-year college, with the sample conditional on taking PLAN. The fourth column assigns zeroes for that college indicator to students not taking PLAN. The fifth column indicates whether a student took PLAN in tenth grade. Below each coefficient is the mean of the outcome variable for students just below the threshold. 
Figure A.1: Distribution of EVAAS Scores
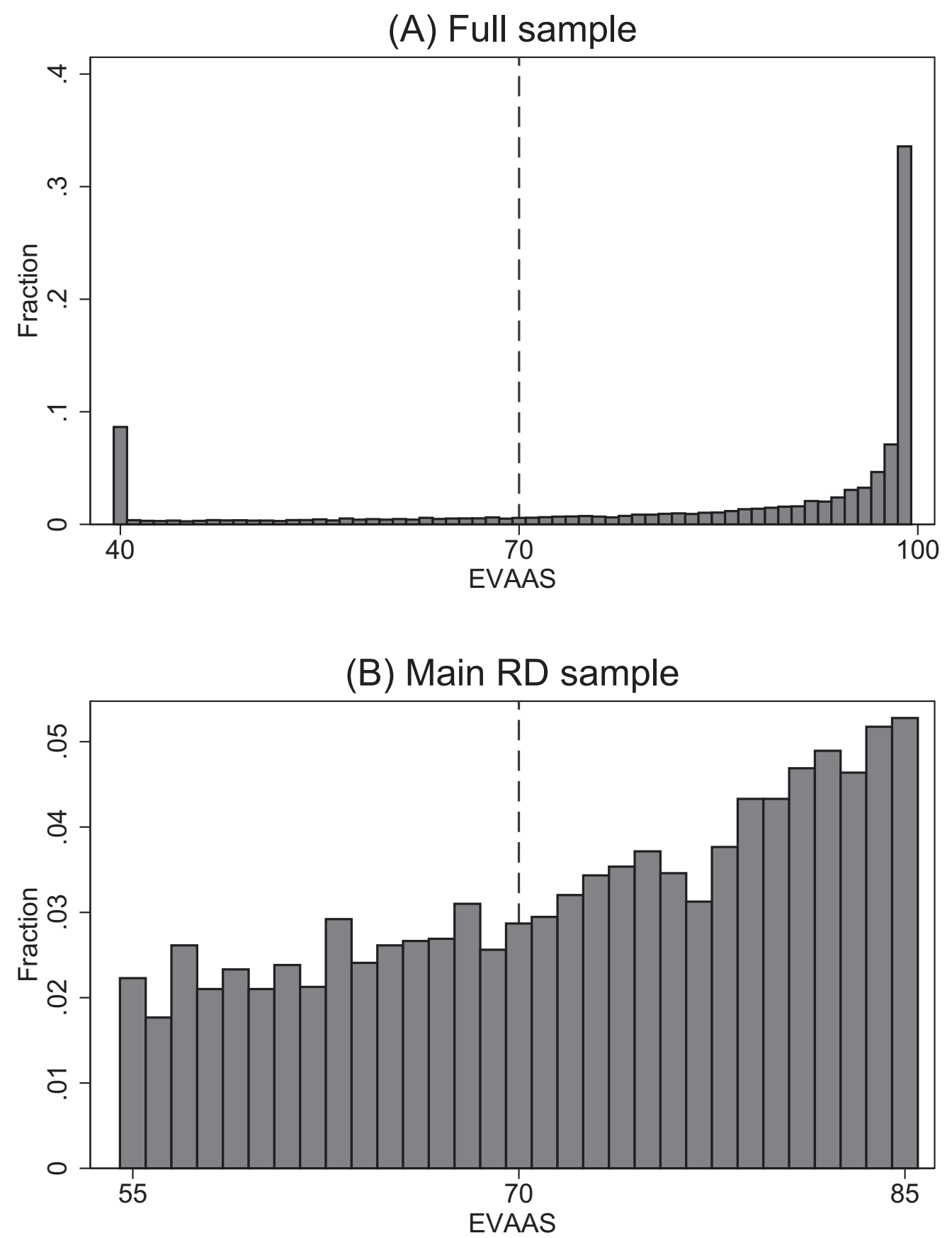

Notes: Shown above is the fraction of students with a given maximum EVAAS score measured prior to seventh grade. EVAAS scores have been collapsed to one-point wide bins. Panel A includes the full sample, with the leftmost bar representing all EVAAS scores less than or equal to 40. Panel B includes the regression discontinuity sample, those with scores between 55 and 85 . 
Figure A.2: First Stage by Income

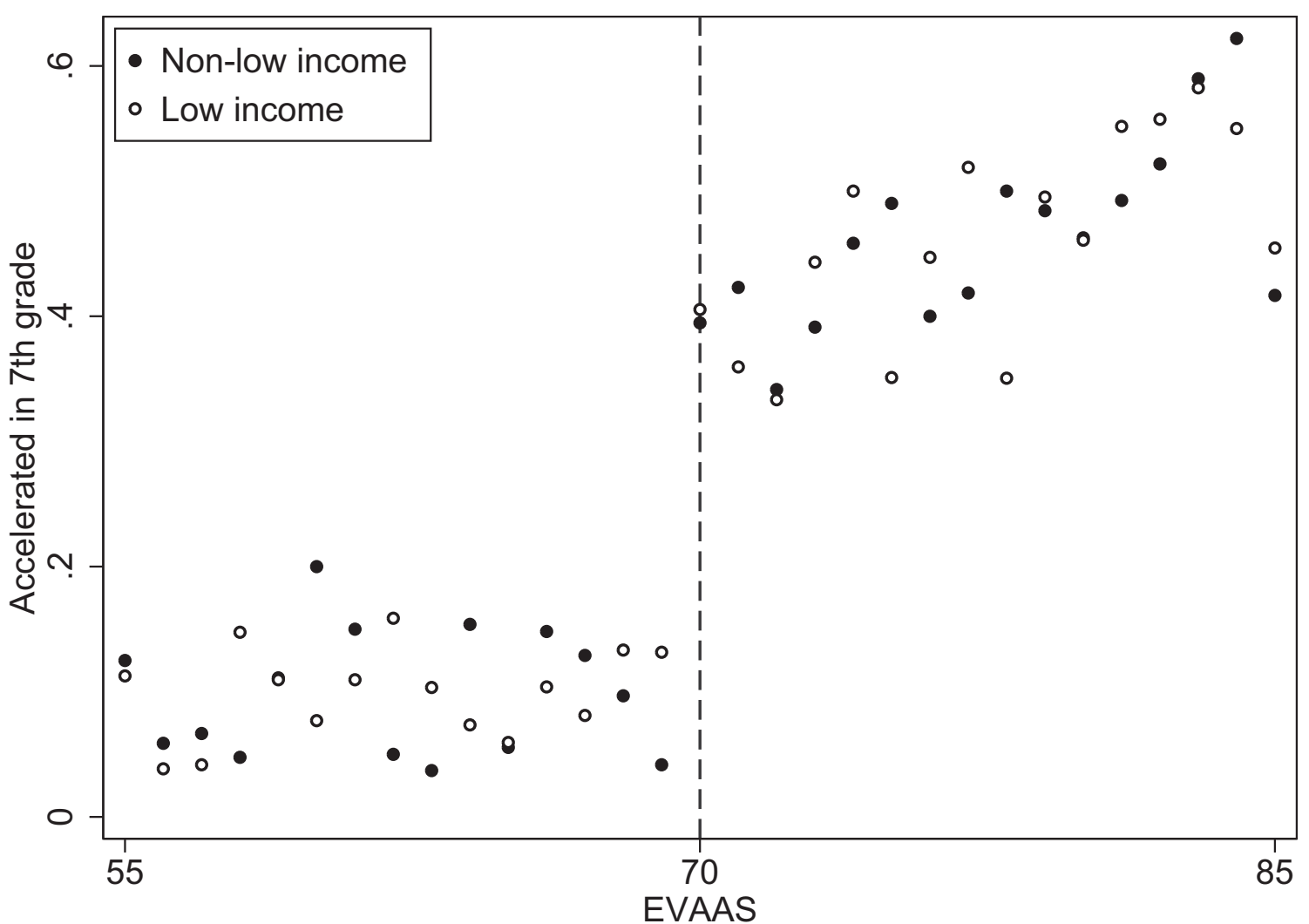

Notes: Shown above is the fraction of low income and non-low income students who enrolled in Pre-Algebra by seventh grade, as a function of their maximum EVAAS score measured prior to seventh grade. EVAAS scores have been collapsed to one-point wide bins. 
Figure A.3: First Stage by Race

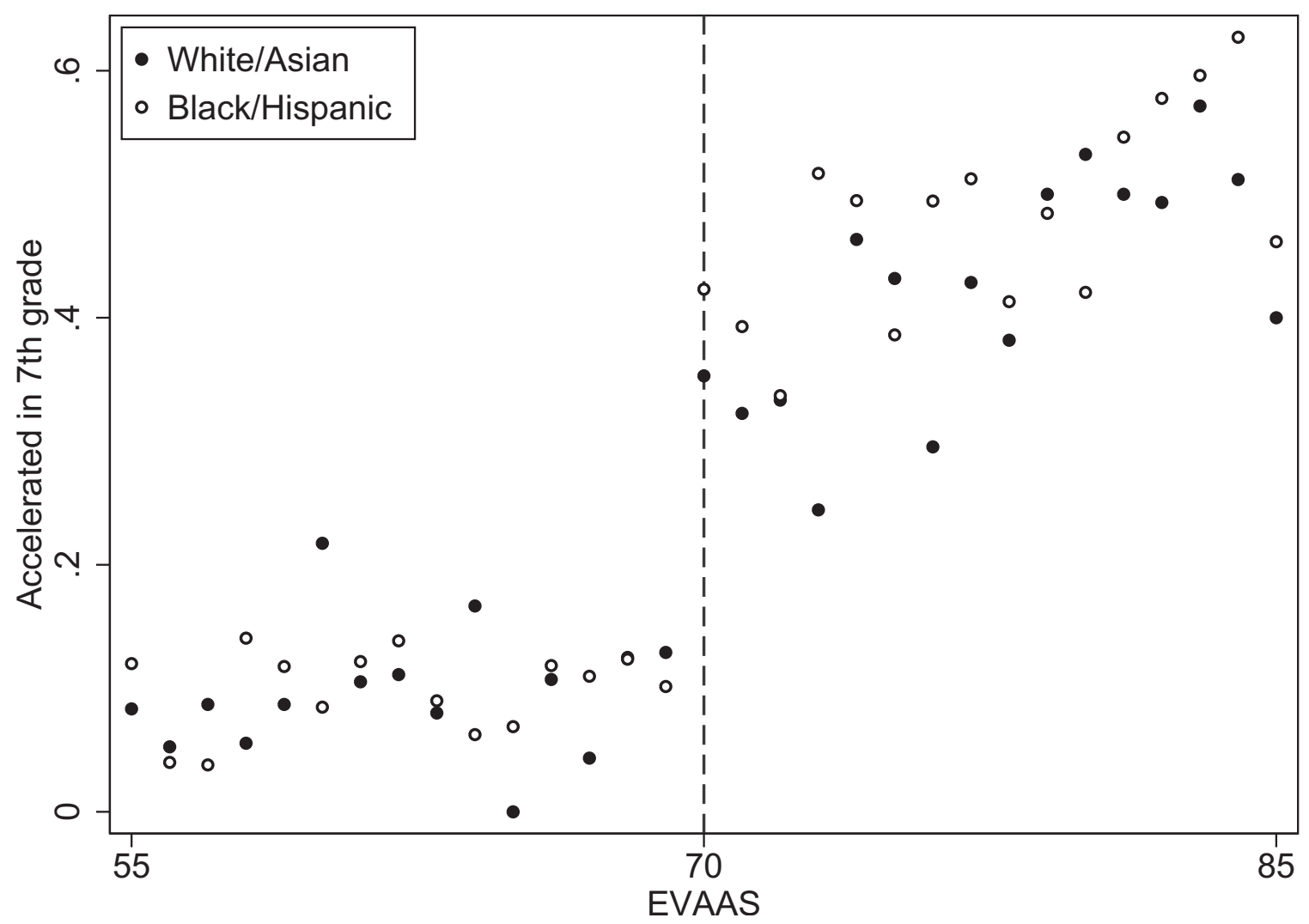

Notes: Shown above is the fraction of black or Hispanic and white or Asian students who enrolled in Pre-Algebra by seventh grade, as a function of their maximum EVAAS score measured prior to seventh grade. EVAAS scores have been collapsed to one-point wide bins. 
Figure A.4: First Stage by Gender

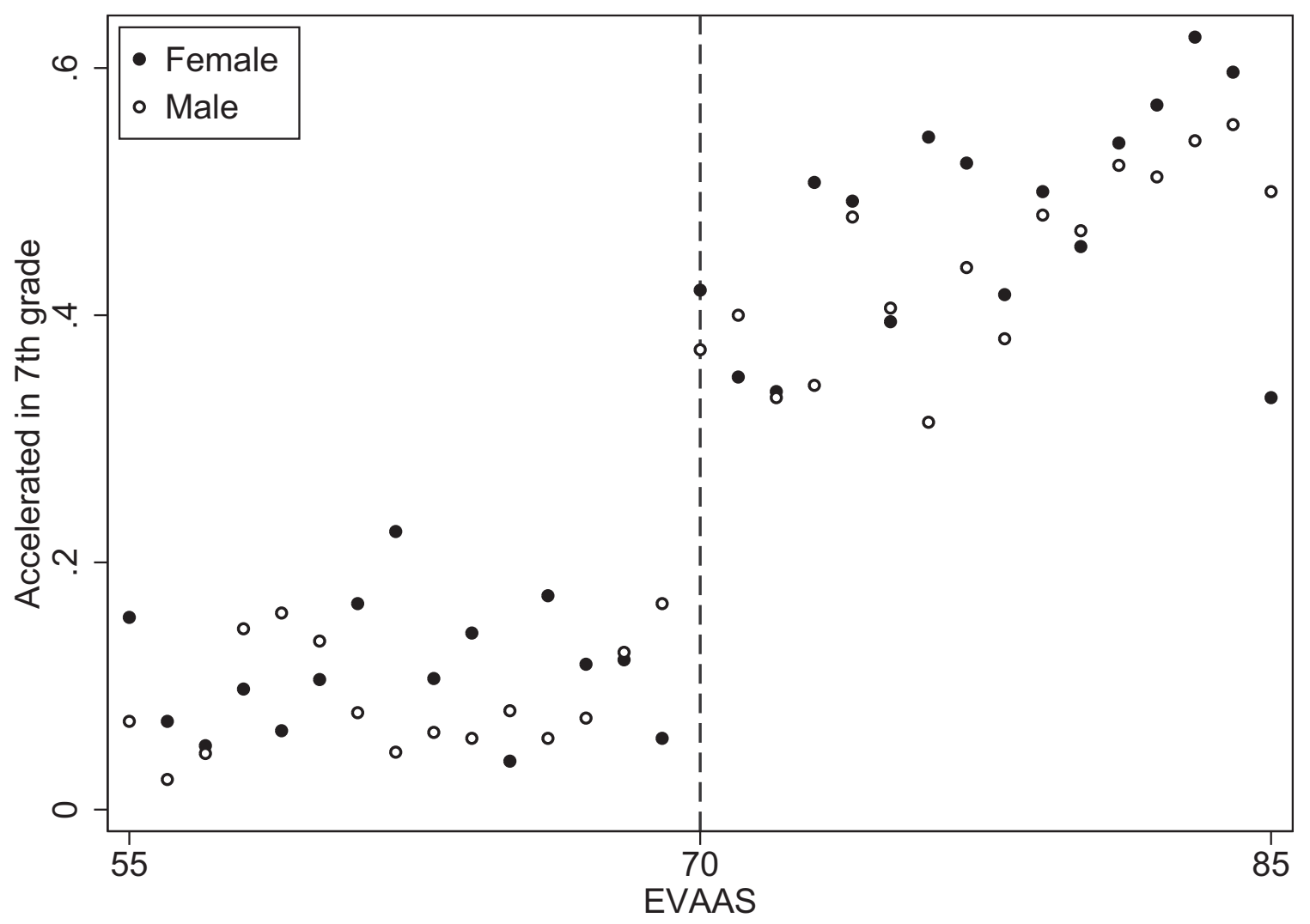

Notes: Shown above is the fraction of male and female students who enrolled in Pre-Algebra by seventh grade, as a function of their maximum EVAAS score measured prior to seventh grade. EVAAS scores have been collapsed to one-point wide bins. 
Table A.1: Covariate Balance

\begin{tabular}{|c|c|c|c|c|}
\hline & $\begin{array}{c}\mathrm{BW}=10 \\
(1)\end{array}$ & $\begin{array}{c}\mathrm{BW}=15 \\
\text { (2) }\end{array}$ & $\begin{array}{c}\mathrm{BW}=20 \\
\text { (3) }\end{array}$ & $\begin{array}{c}\mathrm{BW}=25 \\
(4)\end{array}$ \\
\hline Female & $\begin{array}{c}0.008 \\
(0.042)\end{array}$ & $\begin{array}{c}0.033 \\
(0.038)\end{array}$ & $\begin{array}{c}0.036 \\
(0.038)\end{array}$ & $\begin{array}{c}0.047 \\
(0.029)\end{array}$ \\
\hline Black & $\begin{array}{l}-0.045 \\
(0.048)\end{array}$ & $\begin{array}{l}-0.037 \\
(0.040)\end{array}$ & $\begin{array}{l}-0.030 \\
(0.040)\end{array}$ & $\begin{array}{l}-0.014 \\
(0.033)\end{array}$ \\
\hline Hispanic & $\begin{array}{c}0.022 \\
(0.031)\end{array}$ & $\begin{array}{c}0.020 \\
(0.026)\end{array}$ & $\begin{array}{c}0.008 \\
(0.024)\end{array}$ & $\begin{array}{l}-0.006 \\
(0.022)\end{array}$ \\
\hline Asian & $\begin{array}{l}-0.004 \\
(0.013)\end{array}$ & $\begin{array}{c}0.007 \\
(0.009)\end{array}$ & $\begin{array}{c}0.007 \\
(0.010)\end{array}$ & $\begin{array}{c}0.011 \\
(0.008)\end{array}$ \\
\hline Low income & $\begin{array}{c}-0.070^{*} \\
(0.042)\end{array}$ & $\begin{array}{l}-0.063^{*} \\
(0.034)\end{array}$ & $\begin{array}{c}-0.075^{* *} \\
(0.031)\end{array}$ & $\begin{array}{l}-0.034 \\
(0.024)\end{array}$ \\
\hline 6th grade start age & $\begin{array}{l}-0.001 \\
(0.048)\end{array}$ & $\begin{array}{c}0.003 \\
(0.042)\end{array}$ & $\begin{array}{l}-0.009 \\
(0.035)\end{array}$ & $\begin{array}{l}-0.006 \\
(0.031)\end{array}$ \\
\hline Special education & $\begin{array}{l}-0.015 \\
(0.036)\end{array}$ & $\begin{array}{c}0.015 \\
(0.025)\end{array}$ & $\begin{array}{c}0.006 \\
(0.024)\end{array}$ & $\begin{array}{c}0.010 \\
(0.021)\end{array}$ \\
\hline Limited English proficiency & $\begin{array}{c}0.031 \\
(0.042)\end{array}$ & $\begin{array}{c}0.028 \\
(0.031)\end{array}$ & $\begin{array}{c}0.017 \\
(0.026)\end{array}$ & $\begin{array}{c}0.007 \\
(0.023)\end{array}$ \\
\hline Predicted math score & $\begin{array}{c}0.009 \\
(0.007)\end{array}$ & $\begin{array}{c}0.006 \\
(0.007)\end{array}$ & $\begin{array}{c}0.008 \\
(0.007)\end{array}$ & $\begin{array}{c}0.004 \\
(0.006)\end{array}$ \\
\hline Predicted reading score & $\begin{array}{c}0.014 \\
(0.021)\end{array}$ & $\begin{array}{c}0.011 \\
(0.017)\end{array}$ & $\begin{array}{c}0.019 \\
(0.016)\end{array}$ & $\begin{array}{c}0.012 \\
(0.012)\end{array}$ \\
\hline $\mathrm{N}$ & 2,102 & 3,333 & 4,806 & 6,822 \\
\hline
\end{tabular}

Notes: Heteroskedasticity robust standard errors clustered by initial middle school are in parentheses $(* \mathrm{p}<.10$ $* * \mathrm{p}<.05 * * * \mathrm{p}<.01)$. Estimates show the relationship between initial eligibility and the listed covariate. The coefficients shown are generated by local linear regression using the listed bandwidth and including cohort-bymiddle school fixed effects. Predicted math and reading scores come from regressing fifth grade z-scores on demographic controls for those with valid scores and using the resulting estimates to generate predicted values for all students in the sample. 
Table A.2: Robustness Checks For Seventh Grade Math Scores

\begin{tabular}{|c|c|c|c|c|c|c|}
\hline & $\begin{array}{c}\mathrm{BW}=10 \\
(1)\end{array}$ & $\begin{array}{c}\mathrm{BW}=15 \\
(2)\end{array}$ & $\begin{array}{c}\mathrm{BW}=15 \\
(3)\end{array}$ & $\begin{array}{c}\mathrm{BW}=20 \\
(4)\end{array}$ & $\begin{array}{c}\mathrm{BW}=25 \\
(5)\end{array}$ & $\begin{array}{c}\mathrm{BW}=\mathrm{IK} \\
(6)\end{array}$ \\
\hline All students & $\begin{array}{c}0.056 \\
(0.150)\end{array}$ & $\begin{array}{c}0.006 \\
(0.152)\end{array}$ & $\begin{array}{c}-0.038 \\
(0.156)\end{array}$ & $\begin{array}{c}-0.100 \\
(0.120)\end{array}$ & $\begin{array}{c}0.152 \\
(0.152)\end{array}$ & $\begin{array}{c}0.007 \\
(0.149)\end{array}$ \\
\hline Low income & $\begin{array}{c}-0.124 \\
(0.186)\end{array}$ & $\begin{array}{l}-0.136 \\
(0.182)\end{array}$ & $\begin{array}{l}-0.167 \\
(0.190)\end{array}$ & $\begin{array}{c}-0.248 \\
(0.153)\end{array}$ & $\begin{array}{c}-0.087 \\
(0.193)\end{array}$ & $\begin{array}{l}-0.142 \\
(0.182)\end{array}$ \\
\hline Non-low income & $\begin{array}{c}0.558^{* *} \\
(0.236)\end{array}$ & $\begin{array}{c}0.392^{* *} \\
(0.199)\end{array}$ & $\begin{array}{c}0.382^{*} \\
(0.204)\end{array}$ & $\begin{array}{c}0.190 \\
(0.189)\end{array}$ & $\begin{array}{c}0.611^{* * *} \\
(0.192)\end{array}$ & $\begin{array}{c}0.322 \\
(0.200)\end{array}$ \\
\hline Black/Hispanic & $\begin{array}{c}0.082 \\
(0.169)\end{array}$ & $\begin{array}{c}0.020 \\
(0.171)\end{array}$ & $\begin{array}{c}0.002 \\
(0.172)\end{array}$ & $\begin{array}{l}-0.109 \\
(0.148)\end{array}$ & $\begin{array}{c}0.050 \\
(0.177)\end{array}$ & $\begin{array}{c}0.049 \\
(0.160)\end{array}$ \\
\hline White/Asian & $\begin{array}{l}-0.370 \\
(0.627)\end{array}$ & $\begin{array}{l}-0.117 \\
(0.371)\end{array}$ & $\begin{array}{l}-0.179 \\
(0.393)\end{array}$ & $\begin{array}{l}-0.187 \\
(0.261)\end{array}$ & $\begin{array}{c}0.239 \\
(0.324)\end{array}$ & $\begin{array}{l}-0.073 \\
(0.299)\end{array}$ \\
\hline Male & $\begin{array}{c}0.143 \\
(0.274)\end{array}$ & $\begin{array}{c}0.072 \\
(0.261)\end{array}$ & $\begin{array}{c}0.055 \\
(0.260)\end{array}$ & $\begin{array}{c}-0.135 \\
(0.227)\end{array}$ & $\begin{array}{c}0.179 \\
(0.251)\end{array}$ & $\begin{array}{c}0.116 \\
(0.245)\end{array}$ \\
\hline Female & $\begin{array}{l}-0.055 \\
(0.158)\end{array}$ & $\begin{array}{l}-0.041 \\
(0.144)\end{array}$ & $\begin{array}{c}-0.066 \\
(0.138)\end{array}$ & $\begin{array}{c}-0.074 \\
(0.135)\end{array}$ & $\begin{array}{c}0.093 \\
(0.171)\end{array}$ & $\begin{array}{l}-0.023 \\
(0.142)\end{array}$ \\
\hline Controls & $\mathrm{N}$ & $\mathrm{N}$ & Y & $\mathrm{N}$ & $\begin{array}{l}\mathrm{N} \\
\mathrm{Y}\end{array}$ & $\mathrm{N}$ \\
\hline Quadratic & $\mathrm{N}$ & $\mathrm{N}$ & $\mathrm{N}$ & $\mathrm{N}$ & $\mathrm{Y}$ & $\mathrm{N}$ \\
\hline
\end{tabular}

Notes: Heteroskedasticity robust standard errors clustered by initial middle school are in parentheses $(* \mathrm{p}<.10 * *$ $\mathrm{p}<.05 * * * \mathrm{p}<.01)$. Instrumental variables estimates show the impact of initial math acceleration on seventh grade math scores, standardized within year, where acceleration is instrumented with eligibility. The coefficients shown are generated by local linear regression using the listed bandwidth and including cohort-by-middle school fixed effects. Column 3 includes demographic controls. Column 5 includes quadratic terms in the running variable. The Imbens-Kalyanaraman optimal bandwidths in each row are 14.9, 10.3, 16.3, 10.4, 17.5, 14.4 and 16.4. 
Table A.3: Math Course-Taking by End of High School

\begin{tabular}{lccc}
\hline & $\begin{array}{c}(1) \\
\text { Geometry }\end{array}$ & $\begin{array}{c}(2) \\
\text { Algebra II }\end{array}$ & Pre-calculus \\
\hline Ever took course & 0.190 & 0.019 & 0.104 \\
Mean of the Outcome & $(0.133)$ & $(0.146)$ & $(0.117)$ \\
Ever passed course & 0.74 & 0.58 & 0.38 \\
Mean of the Outcome & 0.143 & 0.001 & 0.049 \\
Ever earned A or B & $(0.141)$ & $(0.140)$ & $(0.111)$ \\
& 0.68 & 0.54 & 0.37 \\
Mean of the Outcome & $0.266^{*}$ & 0.124 & $0.168^{*}$ \\
& $(0.140)$ & $(0.105)$ & $(0.089)$ \\
\hline
\end{tabular}

Notes: Heteroskedasticity robust standard errors clustered by initial middle school are in parentheses $(* \mathrm{p}<.10 * *$ $\mathrm{p}<.05 * * * \mathrm{p}<.01)$. Instrumental variables estimates show the impact of initial math acceleration on ever taking a given math course, where acceleration is instrumented with eligibility. The coefficients shown are generated by local linear regression using a bandwidth of 15 and including cohort-by-middle school fixed effects. Below each coefficient is the mean of the outcome variable for students just below the threshold. The sample size in each regression is 3,333 . 
Table A.4: Robustness Checks for Precalculus Taking

\begin{tabular}{|c|c|c|c|c|c|c|}
\hline & $\begin{array}{c}\mathrm{BW}=10 \\
(1)\end{array}$ & $\begin{array}{c}\mathrm{BW}=15 \\
(2)\end{array}$ & $\begin{array}{c}\mathrm{BW}=15 \\
(3)\end{array}$ & $\begin{array}{c}\mathrm{BW}=20 \\
(4)\end{array}$ & $\begin{array}{c}\mathrm{BW}=25 \\
(5)\end{array}$ & $\begin{array}{c}\mathrm{BW}=\mathrm{IK} \\
(6)\end{array}$ \\
\hline All students & $\begin{array}{l}0.207^{* *} \\
(0.091)\end{array}$ & $\begin{array}{l}0.184^{* *} \\
(0.073)\end{array}$ & $\begin{array}{l}0.138^{* *} \\
(0.067)\end{array}$ & $\begin{array}{c}0.250^{* * *} \\
(0.074)\end{array}$ & $\begin{array}{c}0.214^{* * *} \\
(0.079)\end{array}$ & $\begin{array}{l}0.178^{* *} \\
(0.072)\end{array}$ \\
\hline Low income & $\begin{array}{c}0.033 \\
(0.115)\end{array}$ & $\begin{array}{c}0.055 \\
(0.103)\end{array}$ & $\begin{array}{c}0.045 \\
(0.088)\end{array}$ & $\begin{array}{c}0.077 \\
(0.087)\end{array}$ & $\begin{array}{c}0.019 \\
(0.104)\end{array}$ & $\begin{array}{c}0.048 \\
(0.091)\end{array}$ \\
\hline Non-low income & $\begin{array}{c}0.578^{* * *} \\
(0.175)\end{array}$ & $\begin{array}{c}0.433^{* * *} \\
(0.153)\end{array}$ & $\begin{array}{c}0.414^{* * *} \\
(0.153)\end{array}$ & $\begin{array}{c}0.501^{* *} \\
(0.203)\end{array}$ & $\begin{array}{c}0.530^{* * *} \\
(0.204)\end{array}$ & $\begin{array}{c}0.505^{* *} \\
(0.209)\end{array}$ \\
\hline Black/Hispanic & $\begin{array}{c}0.187^{*} \\
(0.099)\end{array}$ & $\begin{array}{c}0.173^{*} \\
(0.091)\end{array}$ & $\begin{array}{l}0.146 * \\
(0.086)\end{array}$ & $\begin{array}{l}0.205^{* *} \\
(0.084)\end{array}$ & $\begin{array}{c}0.160 \\
(0.101)\end{array}$ & $\begin{array}{c}0.239^{* * *} \\
(0.078)\end{array}$ \\
\hline White/Asian & $\begin{array}{c}0.210 \\
(0.345)\end{array}$ & $\begin{array}{c}0.109 \\
(0.300)\end{array}$ & $\begin{array}{c}0.041 \\
(0.305)\end{array}$ & $\begin{array}{c}0.226 \\
(0.229)\end{array}$ & $\begin{array}{c}0.249 \\
(0.322)\end{array}$ & $\begin{array}{c}0.162 \\
(0.232)\end{array}$ \\
\hline Male & $\begin{array}{c}-0.008 \\
(0.138)\end{array}$ & $\begin{array}{c}0.012 \\
(0.096)\end{array}$ & $\begin{array}{c}-0.055 \\
(0.101)\end{array}$ & $\begin{array}{c}0.108 \\
(0.117)\end{array}$ & $\begin{array}{c}0.118 \\
(0.120)\end{array}$ & $\begin{array}{c}0.027 \\
(0.103)\end{array}$ \\
\hline Female & $\begin{array}{l}0.335^{* *} \\
(0.132)\end{array}$ & $\begin{array}{c}0.333^{* * *} \\
(0.104)\end{array}$ & $\begin{array}{c}0.336^{* * *} \\
(0.100)\end{array}$ & $\begin{array}{c}0.334^{* * *} \\
(0.095)\end{array}$ & $\begin{array}{c}0.300^{* * *} \\
(0.115)\end{array}$ & $\begin{array}{c}0.343^{* * *} \\
(0.093)\end{array}$ \\
\hline Controls & $\mathrm{N}$ & $\mathrm{N}$ & $\mathrm{Y}$ & $\mathrm{N}$ & $\mathrm{N}$ & $\mathrm{N}$ \\
\hline Quadratic & $\mathrm{N}$ & $\mathrm{N}$ & $\mathrm{N}$ & $\mathrm{N}$ & $\mathrm{Y}$ & $\mathrm{N}$ \\
\hline
\end{tabular}

Notes: Heteroskedasticity robust standard errors clustered by initial middle school are in parentheses $(* \mathrm{p}<.10$ $* * \mathrm{p}<.05 * * * \mathrm{p}<.01)$. Instrumental variables estimates show the impact of initial math acceleration on taking precalculus by eleventh grade, where acceleration is instrumented with eligibility. The coefficients shown are generated by local linear regression using the listed bandwidth and including cohort-by-middle school fixed effects. Column 3 includes demographic controls. Column 5 includes quadratic terms in the running variable. The ImbensKalyanaraman optimal bandwidths in each row are 14.6, 18.0, 20.8, 19.1, 19.4, 14.1 and 20.6. 
Table A.5: Robustness Checks for PLAN Scores and College Intentions

\begin{tabular}{|c|c|c|c|c|c|c|}
\hline & $\begin{array}{l}\mathrm{BW}=10 \\
(1)\end{array}$ & $\begin{array}{l}\mathrm{BW}=15 \\
(2)\end{array}$ & $\begin{array}{c}\mathrm{BW}=15 \\
(3)\end{array}$ & $\begin{array}{c}\mathrm{BW}=20 \\
(4)\end{array}$ & $\begin{array}{c}\mathrm{BW}=25 \\
(5)\end{array}$ & $\begin{array}{c}\mathrm{BW}=\mathrm{IK} \\
\text { (6) }\end{array}$ \\
\hline PLAN Composite & $\begin{array}{c}16.154^{* * *} \\
(4.654)\end{array}$ & $\begin{array}{l}13.410^{* * *} \\
(5.086)\end{array}$ & $\begin{array}{c}13.091^{* *} \\
(6.475)\end{array}$ & $\begin{array}{c}6.861 \\
(5.299)\end{array}$ & $\begin{array}{c}17.009^{* * *} \\
(5.488)\end{array}$ & $\begin{array}{l}12.468^{* *} \\
(5.532)\end{array}$ \\
\hline $\mathrm{N}$ & 1,588 & 2,480 & 2,480 & 3,726 & 5,364 & 2,357 \\
\hline PLAN Math & $\begin{array}{c}5.011 \\
(6.745)\end{array}$ & $\begin{array}{c}7.323 \\
(5.791)\end{array}$ & $\begin{array}{c}7.798 \\
(6.968)\end{array}$ & $\begin{array}{c}1.237 \\
(5.517)\end{array}$ & $\begin{array}{c}8.993 \\
(6.187)\end{array}$ & $\begin{array}{c}5.261 \\
(5.628)\end{array}$ \\
\hline $\mathrm{N}$ & 1,599 & 2,491 & 2,491 & 3,743 & 5,387 & 2,626 \\
\hline Took PLAN exam & $\begin{array}{c}0.195 \\
(0.125)\end{array}$ & $\begin{array}{l}0.214^{*} \\
(0.118)\end{array}$ & $\begin{array}{c}0.124 \\
(0.128)\end{array}$ & $\begin{array}{c}0.098 \\
(0.114)\end{array}$ & $\begin{array}{c}0.182 \\
(0.123)\end{array}$ & $\begin{array}{c}0.096 \\
(0.113)\end{array}$ \\
\hline $\mathrm{N}$ & 2,102 & 3,333 & 3,333 & 4,806 & 6,822 & 5,677 \\
\hline $\begin{array}{l}\text { 4-Year college plan } \\
\text { (excluding missing) }\end{array}$ & $\begin{array}{c}0.130 \\
(0.137)\end{array}$ & $\begin{array}{l}0.202^{*} \\
(0.120)\end{array}$ & $\begin{array}{l}0.251^{* *} \\
(0.122)\end{array}$ & $\begin{array}{l}0.195^{*} \\
(0.110)\end{array}$ & $\begin{array}{c}0.183 \\
(0.138)\end{array}$ & $\begin{array}{c}0.176 \\
(0.123)\end{array}$ \\
\hline $\mathrm{N}$ & 1,602 & 2,494 & 2,494 & 3,748 & 5,398 & 3,363 \\
\hline $\begin{array}{l}\text { 4-Year college plan } \\
(\text { missing }=0)\end{array}$ & $\begin{array}{l}0.252^{*} \\
(0.137)\end{array}$ & $\begin{array}{l}0.295^{* *} \\
(0.135)\end{array}$ & $\begin{array}{l}0.288^{* *} \\
(0.134)\end{array}$ & $\begin{array}{l}0.212^{*} \\
(0.114)\end{array}$ & $\begin{array}{l}0.275^{* *} \\
(0.127)\end{array}$ & $\begin{array}{l}0.274^{* *} \\
(0.137)\end{array}$ \\
\hline $\mathrm{N}$ & 2,102 & 3,333 & 3,333 & 4,806 & 6,822 & 3,691 \\
\hline Controls & $\mathrm{N}$ & $\mathrm{N}$ & $\mathrm{Y}$ & $\mathrm{N}$ & $\mathrm{N}$ & $\mathrm{N}$ \\
\hline Quadratic & $\mathrm{N}$ & $\mathrm{N}$ & $\mathrm{N}$ & $\mathrm{N}$ & $\mathrm{Y}$ & $\mathrm{N}$ \\
\hline
\end{tabular}

Notes: Heteroskedasticity robust standard errors clustered by initial middle school are in parentheses $(* \mathrm{p}<.10 * *$ $\mathrm{p}<.05 * * * \mathrm{p}<.01)$. Instrumental variables estimates show the impact of initial math acceleration on 10th grade PLAN percentile scores, where acceleration is instrumented with eligibility. The third row uses an an outcome an indicator for taking the PLAN exam. The fourth row excludes those who did not take the tenth grade PLAN exam, while the fifth row assumes such students do not plan to attend a four-year college. The coefficients shown are generated by local linear regression using the listed bandwidth and including cohort-by-middle school fixed effects. Column 3 includes demographic controls. Column 5 includes quadratic terms in the running variable. The Imbens-Kalyanaraman optimal bandwidths in each row are 14.2, 14.8, 22.8, 18.1 and 16.4. 
Table A.6: College Readiness Scores and Enrollment Plans

\begin{tabular}{|c|c|c|c|c|c|}
\hline & $\begin{array}{c}(1) \\
\text { PLAN } \\
\text { composite } \\
\text { percentile }\end{array}$ & $\begin{array}{c}(2) \\
\text { PLAN } \\
\text { math } \\
\text { percentile }\end{array}$ & $\begin{array}{l}\text { (3) } \\
\text { Plans for } \\
\text { four-year } \\
\text { college }\end{array}$ & $\begin{array}{l}\text { (4) } \\
\text { Plans for } \\
\text { four-year } \\
\text { college }\end{array}$ & $\begin{array}{c}(5) \\
\text { Took } \\
\text { PLAN } \\
\text { exam }\end{array}$ \\
\hline Non-low income & $\begin{array}{l}14.727^{*} \\
(8.678)\end{array}$ & $\begin{array}{c}7.641 \\
(8.281)\end{array}$ & $\begin{array}{c}0.114 \\
(0.202)\end{array}$ & $\begin{array}{c}0.230 \\
(0.223)\end{array}$ & $\begin{array}{c}0.153 \\
(0.187)\end{array}$ \\
\hline Mean of the Outcome & 36.27 & 35.37 & 0.65 & 0.54 & 0.83 \\
\hline $\mathrm{N}$ & 887 & 889 & 889 & 1,049 & 1,049 \\
\hline Low income & $\begin{array}{l}11.960 \\
(9.274)\end{array}$ & $\begin{array}{c}9.363 \\
(8.832)\end{array}$ & $\begin{array}{c}0.373^{*} \\
(0.205)\end{array}$ & $\begin{array}{l}0.331^{* *} \\
(0.154)\end{array}$ & $\begin{array}{c}0.112 \\
(0.141)\end{array}$ \\
\hline Mean of the Outcome & 28.82 & 28.95 & 0.59 & 0.39 & 0.66 \\
\hline $\mathrm{N}$ & 1,591 & 1,600 & 1,603 & 2,271 & 2,271 \\
\hline White/Asian & $\begin{array}{c}4.125 \\
(17.315)\end{array}$ & $\begin{array}{c}-1.057 \\
(19.104)\end{array}$ & $\begin{array}{c}0.274 \\
(0.370)\end{array}$ & $\begin{array}{c}0.290 \\
(0.336)\end{array}$ & $\begin{array}{c}0.148 \\
(0.267)\end{array}$ \\
\hline Mean of the Outcome & 38.25 & 37.00 & 0.58 & 0.47 & 0.80 \\
\hline $\mathrm{N}$ & 777 & 779 & 780 & 989 & 989 \\
\hline Black/Hispanic & $\begin{array}{c}12.320^{* *} \\
(6.051)\end{array}$ & $\begin{array}{c}6.930 \\
(6.012)\end{array}$ & $\begin{array}{c}0.216 \\
(0.149)\end{array}$ & $\begin{array}{c}0.266^{* *} \\
(0.135)\end{array}$ & $\begin{array}{c}0.106 \\
(0.114)\end{array}$ \\
\hline Mean of the Outcome & 28.13 & 28.33 & 0.63 & 0.42 & 0.67 \\
\hline $\mathrm{N}$ & 1,595 & 1,603 & 1,605 & 2,180 & 2,180 \\
\hline Female & $\begin{array}{l}10.037 \\
(7.896)\end{array}$ & $\begin{array}{l}-4.247 \\
(8.529)\end{array}$ & $\begin{array}{c}0.078 \\
(0.177)\end{array}$ & $\begin{array}{c}0.214 \\
(0.227)\end{array}$ & $\begin{array}{c}0.243 \\
(0.190)\end{array}$ \\
\hline Mean of the Outcome & 33.84 & 32.55 & 0.69 & 0.51 & 0.73 \\
\hline $\mathrm{N}$ & 1,344 & 1,350 & 1,351 & 1,724 & 1,724 \\
\hline Male & $\begin{array}{c}12.340 \\
(10.119)\end{array}$ & $\begin{array}{l}18.345^{*} \\
(9.559)\end{array}$ & $\begin{array}{l}0.436^{* *} \\
(0.202)\end{array}$ & $\begin{array}{c}0.362^{* *} \\
(0.170)\end{array}$ & $\begin{array}{c}-0.015 \\
(0.148)\end{array}$ \\
\hline Mean of the Outcome & 27.95 & 29.02 & 0.52 & 0.35 & 0.67 \\
\hline $\mathrm{N}$ & 1,135 & 1,140 & 1,142 & 1,592 & 1,592 \\
\hline
\end{tabular}

Notes: Heteroskedasticity robust standard errors clustered by initial middle school are in parentheses $(* \mathrm{p}<.10$ $* * \mathrm{p}<.05 * * * \mathrm{p}<.01)$. Instrumental variables estimates show the impact of initial math acceleration on the listed outcome on the tenth grade PLAN exam, where acceleration is instrumented with eligibility. The coefficients shown are generated by local linear regression using a bandwidth of 15 and including cohort-by-middle school fixed effects. Outcomes in the first two columns are nationally normed percentile scores on the overall PLAN exam and its math component. The third column indicates whether a student intends to attend a four-year college, with the sample conditional on taking PLAN. The fourth column assigns zeroes for that college indicator to students not taking PLAN. The fifth column indicates whether a student took PLAN in tenth grade. Below each coefficient is the mean of the outcome variable for students just below the threshold. 